Josilene da Silva

Ocorrência de pesticidas organoclorados e bifenilos policlorados em tartarugas marinhas Chelonia mydas.

Dissertação apresentada ao Instituto

Oceanográfico da Universidade de São

Paulo, como parte dos requisitos para obtenção do título de Mestre em Ciências, área de Oceanografia Química e Geológica.

Orientadora: Profa. Dra. Rosalinda Carmela Montone

São Paulo 
Universidade de São Paulo

Instituto Oceanográfico

\title{
Ocorrência de pesticidas organoclorados e bifenilos policlorados em tartarugas marinhas Chelonia mydas
}

\begin{abstract}
Josilene da Silva
Dissertação apresentada ao Instituto Oceanográfico da Universidade de São Paulo, como parte dos requisitos para obtenção do título de Mestre em Ciências, área de Oceanografia Química e Geológica.
\end{abstract}

Julgada em por

Profa. Dra. Rosalinda Carmela Montone

Conceito Departamento de Oceanografia Física do Instituto Oceanográfico da Universidade de São Paulo

$\operatorname{Prof(a).~Dr(a).~}$

Conceito

$\operatorname{Prof}(\mathrm{a}) \cdot \operatorname{Dr}(\mathrm{a})$

Conceito 
DEDICO ESTE TRABALHO AOS MEUS PAIS E IRMÃOS . 
Deus caprichou, mas escondeu tudo debaixo d'água.

Vagner Simonetti 


\section{Sumário}

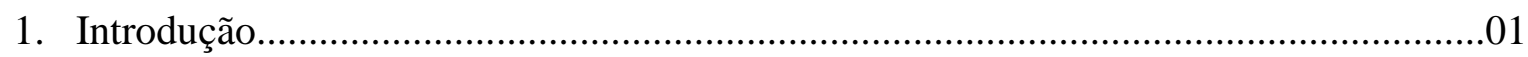

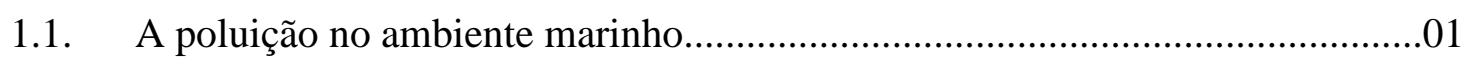

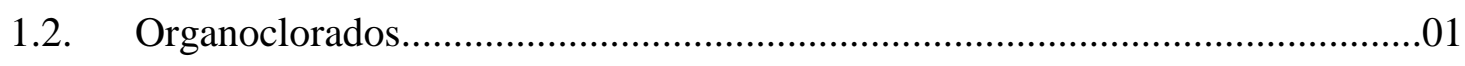

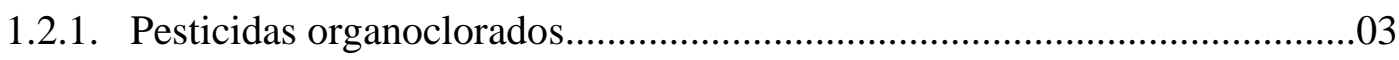

1.2.1.1. Diclorodifeniltricloroetano (DDT) …...........................................

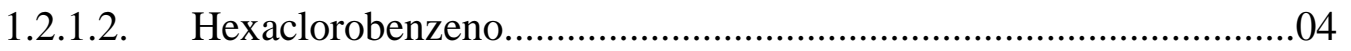

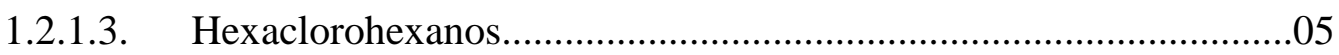

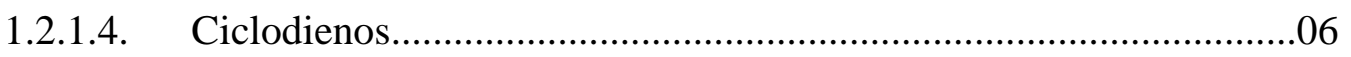

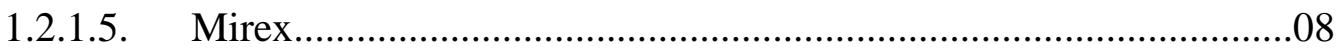

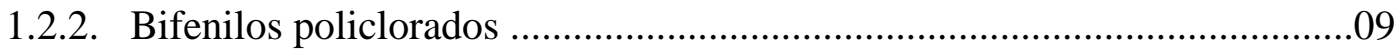

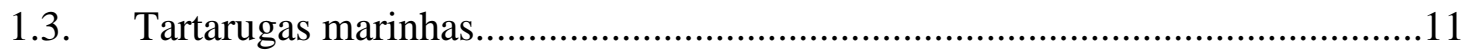

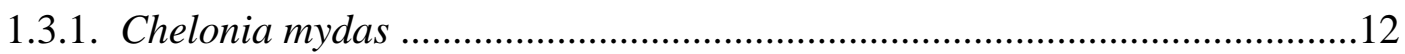

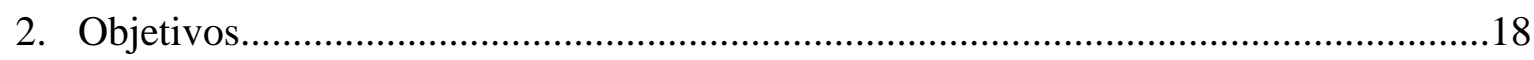

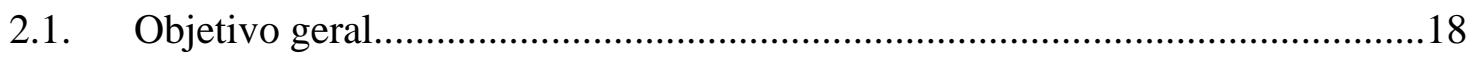

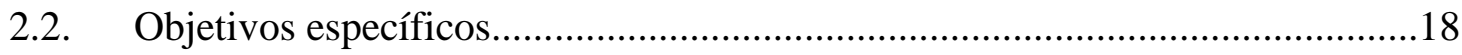

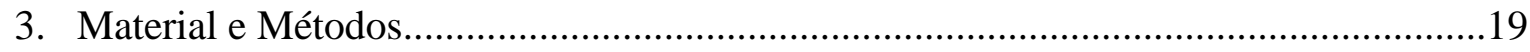

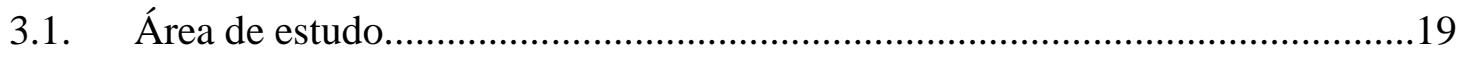

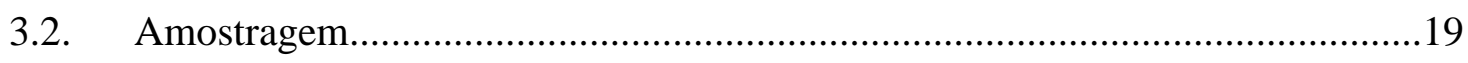

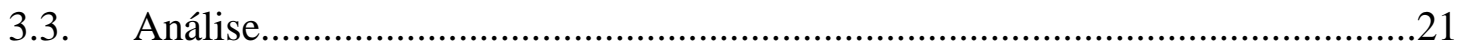

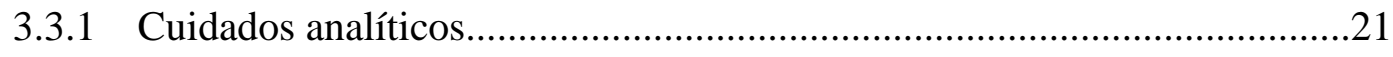

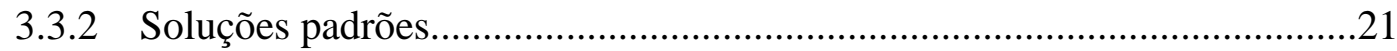

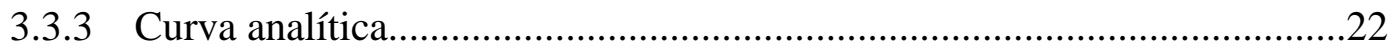

3.3.4 Preparação das amostras para análise de organoclorados.........................22

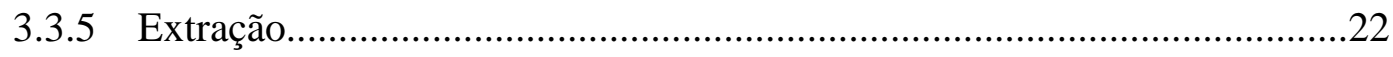




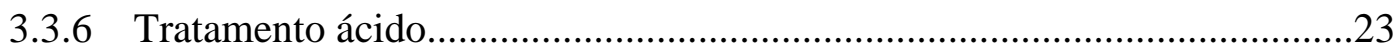

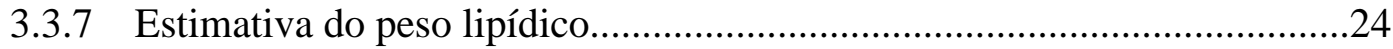

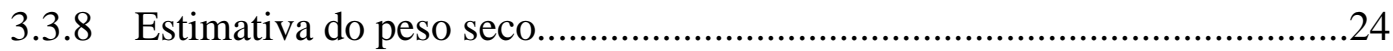

3.3.9 Análise dos compostos por cromatografia em fase gasosa (GC)...............25

3.3.10 Limite de detecção do método...............................................................26

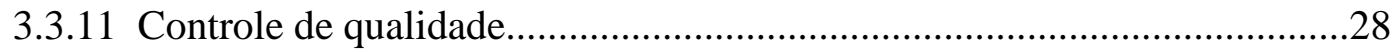

3.3.12 Material de referência certificado...............................................................

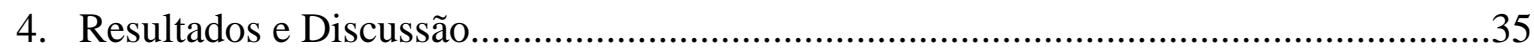

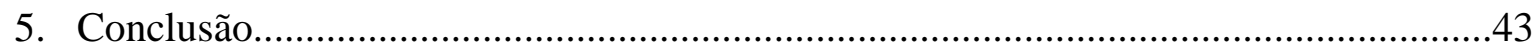

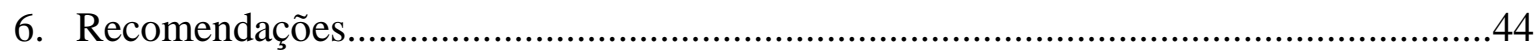

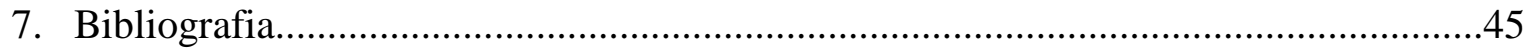

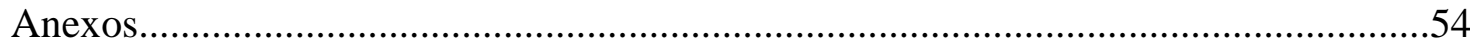




\section{Lista de Figuras}

Figura 01. DDT e seus metabólitos .04

Figura 02. Hexaclorobenzeno. .05

Figura 03. Isômeros do hexaclorociclohexano $(\mathrm{HCH})$. .06

Figura 04. Estrutura química do aldrin, dieldrin, endrin .07

Figura 05. Formas cis e trans do Clordano .07

Figura 06. Estrutura química do Heptacloro e Heptacloro epóxido. .08

Figura 07. Mirex

Figura 08. Bifenilos policlorados.

Figura 09. Estruturas da cabeça importantes para identificação da espécie Chelonia mydas..13

Figura 10. Estruturas morfológicas externas da carapaça e do plastrão de uma tartaruga marinha

Figura 11. Distribuição das escamas da carapaça, do plastrão e da cabeça da espécie

Chelonia mydas. .14

Figura 12. Mapa da região de Ubatuba, adaptado de Gallo et al. (2006)..... 19

Figura 13. Fluxograma do experimento analítico .25

Figura 14. Cromatograma obtido para o material de referência no GC-ECD. .34

Figura 15. Cromatograma e exemplo do espectro de massas do PCB 153 obtidos para o material de referência no GC-MS. 34

Figura 16. Avaliação da normalidade dos dados usando gráfico quantil-quantil (q-q) para amostras de tecidos de C. mydas. .37

Figura 17. Boxplot da concentração de PCBs nos tecidos de gordura, fígado e rim em

C. mydas .38

Figura 18. Perfil da ocorrência dos PCBs na gordura, fígado e rim em tartarugas 
Figura 19. Frequência de ocorrência de PCBs conforme o número de cloros por tecidos.......42

Figura 20. Frequência de ocorrência dos congêneres nas amostras de gordura analisadas......42

\section{Lista de tabelas}

Tabela 01. Sexo, biometria $(\mathrm{CC}=$ comprimento da carapaça, $\mathrm{LC}=$ largura da carapaça e peso $)$ e condição dos indivíduos da espécie Chelonia mydas coletadas para o presente trabalho.......20

Tabela 02. Limite de detecção do método (LDM) para PCBs em tecidos...............................27

Tabela 03. Limite de detecção método (LDM) para Pesticidas em tecidos..............................28

Tabela 04. Recuperação (\%) dos padrões internos (PI) e dos 52 PCBs analisados para o branco fortificado e a amostra fortificada no controle de qualidade .30

Tabela 05. Recuperação (\%) dos padrões internos (PI) e dos pesticidas analisados para o branco fortificado e a amostra fortificada no controle de qualidade 31

Tabela 06. Resultados obtidos na análise do material de referência certificado SRM 1945 .33

Tabela 07. Concentração de PCBs (ng. $\mathrm{g}^{-1}$ ) nas amostras de gordura, fígado e rim de fêmeas e machos da espécie $C$. mydas. .36

Tabela 08. Comparação na concentração $\left(n g \cdot \mathrm{g}^{-1}\right)$ de compostos organoclorados em diferentes espécies de tartaruga marinha. 40 


\section{Agradecimentos}

Em primeiro lugar agradeço a Deus por ter me dado saúde, força e a ajuda da Satie para concluir esse trabalho.

Agradeço aos meus pais, Gentil e Palmira, que sempre me apoiaram e respeitaram minhas escolhas. Aos meus irmãos e seus respectivos, Bel e Luiz, Lau e Celi, Wagner e Lud, que são verdadeiros anjos da guarda sempre me tirando de todas as encrencas em que eu me metia, e não foram poucas. Aos meu sobrinhos Zeca e Rafa por todo o carinho e momentos de diversão.

Agradeço a minha orientadora Rosa por ter me aceito em sua equipe e me ajudado a realizar este trabalho.

À Jovial (Márcia) pela amizade, conversas, por me mandar para Abrolhos duas vezes, por pegar no meu pé (muito). Ao Rolf pelas conversas e hidromel.

À Satie por ter me ensinado praticamente tudo o que precisei para concluir esse trabalho, pela paciência, carinho e amizade. Ao Lourival por sempre estar presente e me explicando as coisas com toda calma do mundo, por não me matar quando eu quebrava alguma coisa no laboratório e por todo carinho. Ao Silvio pelas "longas" conversas, pela amizade, paciência e ajuda. À Verinha pela amizade e carinho.

Aos amigos que pertencem ou já pertenceram ao "Cantinho da Vadiagem": Ana Cecília (companheira, lesada, alienada, muito querida), Diego (amigo, pentelho e pelo chocolate de ovomaltine), Fernanda (sempre respondendo as minhas perguntas toscas e por me agüentar como "vela" por uma semana em Maceió), Patrick (por macerar minhas amostras e pelo carinho), Hil (amiga, chata, pentelha, por toda ajuda e carinho), Vinicius (por ter abusado da sua boa vontade), Eliete (pela amizade e conversas), Caio "legal" (pela companhia nas pedaladas e pelas comidinhas), “Caio Bonitão"(muito pentelho), Edgar (também conhecido 
como "Matador", grande amigo), Ielou (também conhecido como Rafael, mais pentelho que o bonitão), Juliana ( pela amizade, carinho, paciência, por toda ajuda, pela companhia, conversas e por derrubar cerveja no meu pastel), Mauro, Bia, Carolzinha, César, Denis, Mauricio e Mariana.

Ao amigos do DOB pelos momentos nos embarque, festinhas, idas aos bares, cafezinhos, e por todo carinho, Sandrinha (te gosto muito), Caia, Betina, Paulinha, Fred, Paulinho, Natalia, Cau, Arthur, Bica, Déia, Mau, Mauro, Fabio, Thais (pela amizade e por emprestar o carro em Ubatuba para buscar minhas amostras), Zezé (por "gostar" tanto de $\operatorname{mim})$.

Aos anexos Filipe (Ju), Michel (Fer), Vito (Satie), Fernando (Hil), Thais (Di), Flavia (Edgar), Patrícia (Silvio), João (Verinha) e Rubens.

Ao Projeto TAMAR-IBAMA por fornecer as amostras para realizar esse trabalho. Em especial pela ajuda do veterinário Max Werneck.

Ao amigo Fernandão por sempre estar presente.

Aos meus grandes amigos Eric, Guilherme e Luca por me alegrarem e brincarem comigo.

À amiga Silmara pela convivência e conversas sobre nossas dissertações.

À toda equipe da biblioteca, em especial à Cida, Wagner, Claudia e Raimunda.

Ao Sal que me apoio e suportou as minhas crises no fim da dissertação. 


\section{Resumo}

Os compostos organoclorados (OCs), como pesticidas e bifenilos policlorados (PCBs), são persistentes, tóxicos e amplamente distribuídos através do transporte atmosférico e correntes oceânicas. Poucos são os estudos realizados de OCs em tartarugas, sendo que nenhum foi realizado na costa brasileira. A Chelonia mydas é a maior tartaruga marinha de carapaça dura, que se distribue por todos os oceanos, nas zonas de águas tropicais e subtropicais. O presente trabalho visa verificar a ocorrência de organoclorados na espécie $C$. mydas, bem como sua possível relação com algum tipo de alteração morfológica ou fisiológica. Foram coletadas amostras de gordura, fígado, rim e músculo em 27 espécimes juvenis do litoral de Ubatuba, São Paulo. Os organoclorados foram extraídos com solventes orgânicos e o extrato foi purificado com ácido concentrado. A identificação e quantificação dos PCBs e pesticidas foram realizadas em cromatógrafo a gás com espectrômetro de massas e com detector de captura de elétrons, respectivamente. Os pesticidas organoclorados não foram detectados em nenhuma amostra. As concentrações de PCBs totais em peso úmido foram de: <1,6 - 48,9 ng. $\mathrm{g}^{-1}$ em gordura, $<1,6-17,4 \mathrm{ng} \cdot \mathrm{g}^{-1}$ no fígado e $<1,6-9,2 \mathrm{ng} \cdot \mathrm{g}^{-1}$ no rim. Os baixos níveis encontrados estão relacionados principalmente a sua dieta alimentar, uma vez que a C. mydas é basicamente herbívora, e ao local de coleta, que é uma região não industrializada. 


\begin{abstract}
Organochlorine compounds, such as pesticides and polychlorinated biphenyls (PCBs), are persistent, toxics and widely distributed due to the atmospheric transport and oceanic currents. Few studies have reported the occurrence of these compounds in turtles, but none from the Brazilian Coast. Chelonia mydas is the biggest marine turtle with hard carapace that extends throughout tropical and subtropical seas around the world. The present study aims to assess the concentrations of organochlorines in the $C$. mydas as well as any relationship with morphological or physiological variations. Fat, liver and kidney samples were collected from 27 juvenile specimens found dead in Ubatuba Coast, São Paulo State. Organochlorine were extracted with organic solvents and the extracts were purified with concentrated acid. PCBs and pesticides were identified and quantified using a gas chromatograph with mass spectrometer and with electron capture detector, respectively. Pesticides were not detected in any sample analyzed. PCBs concentrations in wet weight were: $<1.6-48.9 \mathrm{ng} \cdot \mathrm{g}^{-1}$ in fat, $<1.6$ - $17.4 \mathrm{ng} \cdot \mathrm{g}^{-1}$ in liver and $<1.6-9.2 \mathrm{ng} . \mathrm{g}^{-1}$ in kidney. The low levels detected are related, especially, to the feeding habits of the species since $C$. mydas is mainly herbivore, and to a non industrialized sampling area.
\end{abstract}




\section{Introdução}

\subsection{A poluição no ambiente marinho}

Poluição marinha é definida como a "introdução, pelo homem, de substâncias ou energia no ambiente marinho (incluindo estuários), acarretando em efeitos deletérios, como danos aos recurso vivos, doenças à saúde humana e obstáculo às atividades marinhas, incluindo pesca e lazer, ocasionando redução da qualidade de vida". Desde o aparecimento do homem, os mais variados resíduos têm sido produzidos e lançados nos rios, mares e na atmosfera, dentre quais vários mostram-se tóxicos (JÚNIOR et al, 2002).

Os oceanos e os mares funcionam, de forma direta ou indireta, como receptáculos de uma grande variedade de contaminantes gerados pela atividade humana. As principais vias de transporte de poluentes para o ambiente marinho são o escoamento superficial dos continentes, os rios e a atmosfera. Os poluentes que atingem o ambiente marinho podem ser provenientes de rejeitos urbanos, agrícolas e industriais e classificados de diversas formas, sendo que uma delas baseia-se na persistência no ambiente, como no caso dos organoclorados (CLARK, 2001).

Os organoclorados são compostos altamente tóxicos, como os pesticidas que foram empregados no controle de pragas e os bifenilos policlorados que foram muito utilizados como fluidos refrigerantes em transformadores, condensadores elétricos, plastificantes em PVC, fluido de transferência de calor em maquinaria, impermealizantes entre outras aplicações. (BAIRD, 2002).

\subsection{Organoclorados}

Os compostos organoclorados (OCs) são hidrocarbonetos clorados sintéticos. Eles podem ser divididos em dois grupos: baixo e alto peso molecular. Os organoclorados de baixo peso molecular são constituídos pelos solventes industriais e pelos freons, também conhecidos 
como clorofluorcarbonos (CFCs). Esses compostos são voláteis, possuem baixa acumulação na biota e não são encontrados em grandes concentrações no sistema aquático. Portanto, seu principal impacto direto no ambiente está associado à atmosfera. Os organoclorados de alto peso molecular como pesticidas e bifenilos policlorados representam uma preocupação em especial, pois ao contrário dos de baixo peso molecular, provocam grande impacto no sistema aquático, bioacumulando nos organismos e podendo causar efeitos adversos (CLARK, 2001).

Os pesticidas organoclorados e bifenilos policlorados (PCBs) são compostos, que devido as suas características físico-químicas, são persistentes, tóxicos e podem ser amplamente distribuídos pelo globo através do transporte atmosférico e correntes oceânicas, além de bioacumularem e biomagnificarem ao longo da cadeia trófica. Devido a essas características esses compostos fazem parte de um grupo que foram classificados como poluentes orgânicos persistentes (POPs) pela United Nations Environment Programme (PNUMA, 2002).

Ainda que se desconheça que muitos dos organoclorados são perigosos, um número substancial deles apresenta grandes riscos. Na maioria, esses riscos englobam três características comuns. Os organoclorados são muito estáveis e persistentes no ambiente, daí o atrativo de sua fabricação. Tendem a ser solúveis nas gorduras, podendo ser bioacumulados Muitos tem uma toxicidade crônica, o que significa que, a exposição a longo prazo pode ser perigosa. As razões para toxicidade variam. Alguns organoclorados podem imitar substâncias químicas naturais, como os hormônios, e podem perturbar os processos químicos dos organismos vivos, alguns debilitam o sistema imunológico, outros afetam o desenvolvimento dos órgãos e muitos promovem o câncer e assim sucessivamente (SANTAMARTA, 2001). 


\subsubsection{Pesticidas organoclorados}

Os pesticidas organoclorados formam a primeira geração de praguicidas usados pelo homem em larga escala. Devido às suas propriedades inseticidas e grande efeito residual, eles foram extensamente utilizados em todo o mundo como defensivos agrícolas e campanhas de saúde pública, principalmente após o início da Segunda Guerra Mundial (YOGUI, 2002).

Apesar de serem muito úteis no controle de vetores de doenças transmissíveis, na redução de plantas aquáticas em reservatórios e na agricultura, também causam sérios danos no ambiente. Alguns apresentam efeitos persistentes no ambiente, e se acumulam nos tecidos gordurosos dos organismos e outros são metabolizados (CETESB, 1978).

\subsubsection{Diclorodifeniltricloroetano (DDT)}

O DDT é um inseticida que foi sintetizado em 1874, mas suas propriedades praguicidas só foram conhecidas em 1939 e foi produzido em grande escala em 1962. Tipicamente, a exposição humana e animal não ocorre apenas ao DDT mas também ao DDE e DDD que são produtos de degradação ambiental e são produzidos no processo de biotransformação do DDT (Figura 01). A acentuada atividade inseticida aliada à prolongada ação residual, bem como a baixa toxicidade aguda para mamíferos e o baixo custo, fizeram com que seu uso rapidamente se expandisse no controle das pragas agrícolas, e nos programas de saúde pública para combater vetores transmissores de doenças como: febre amarela, malária, tifo, dengue e outras. Na Suécia e Estados Unidos seu uso foi proibido na década de 70 e no Brasil a proibição ocorreu em 1985. Atualmente o seu emprego é limitado ao controle de zoonoses em países em desenvolvimento. Em consequência do uso indiscriminado no passado e da persistência no ambiente, o DDT e seus produtos de degradação (DDD e DDE) tornaram-se substâncias ubíquas na natureza. O DDT pode alcançar a atmosfera através da evaporação dos resíduos presentes no solo e na água, ou durante sua aplicação no controle de vetores, 
particularmente quando esta é efetuada por aviões. Uma vez na atmosfera, as partículas são impulsionadas pelos ventos para longe da fonte de aplicação. Os DDTs podem ser absorvidos diretamente através do meio ambiente, ou através da cadeia alimentar. A via digestiva é considerada a mais significativa via de entrada do DDT no organismo humano, devido ao consumo de alimentos ou uso de utensílios contaminados a absorção se faz principalmente no intestino. Os efeitos do DDT nos organismos biológicos incluem neurotoxicidade, hepatotoxicidade, efeitos metabólicos, efeitos reprodutivos e câncer (JESUS, 2002).<smiles>Clc1ccc(C(c2ccccc2Cl)C(Cl)Cl)cc1</smiles>
o,p'-DDE<smiles>Clc1ccc(C(c2ccc(Cl)cc2)C(Cl)(Cl)Cl)cc1</smiles>
$\mathrm{p}, \mathrm{p}-\mathrm{DDT}$<smiles>Clc1ccc(C(c2ccccc2Cl)C(Cl)(Cl)Cl)cc1</smiles>

o,p'-DDT<smiles>Clc1ccc(C(c2ccc(Cl)cc2)C(Cl)Cl)cc1</smiles>
$p, p^{\prime}-D D D$<smiles>Clc1ccc(C(c2ccccc2Cl)C(Cl)Cl)cc1</smiles>

$0, p^{\prime}-\mathrm{DDD}$<smiles>ClC(Cl)=C(c1ccc(Cl)cc1)c1ccc(Cl)cc1</smiles>

$p, p^{\prime}-D D E$

Figura 01. DDT e seus metabólitos.

\subsubsection{Hexaclorobenzeno (HCB)}

$\mathrm{O} \mathrm{HCB}$, por apresentar atividade fungicida, foi utilizado na agricultura no tratamento de sementes de produtos agrícolas para impedir o crescimento de fungos (Figura 02). Na indústria foi usado diretamente na fabricação de fogos de artifício, na fabricação de alumínio e como agente preservador de madeira. Embora a produção de HCB tenha cessado na maioria dos países, ele ainda pode ser gerado como subproduto e/ou impureza em muitos processos químicos. Entre as principais fontes de HCB no meio ambiente estão fábricas de solventes 
clorados, a fabricação e a aplicação de pesticidas contaminados por HCB e a incineração inadequada de lixo contendo cloro. O HCB pode ser absorvido pelas vias cutânea, respiratória e digestiva. A exposição crônica ao HCB provoca danos hepáticos e tumores nos rins, bem como alterações gástricas (TOLEDO, 2002).

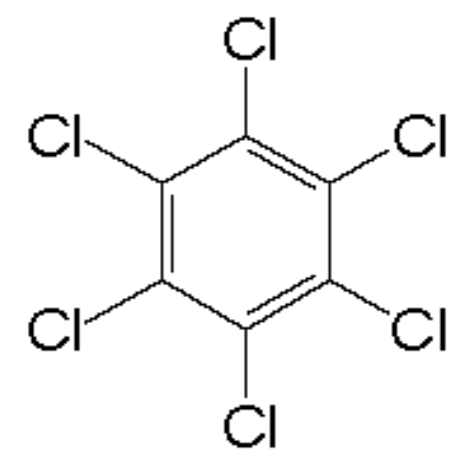

Figura 02. Hexaclorobenzeno.

\subsubsection{Hexaclorociclohexanos (HCHs)}

O HCH foi sintetizado pela primeira vez em 1825 e teve grande utilização nas décadas de 60 e 70 (Figura 03). A sua fabricação foi interrompida na maioria dos países produtores na década de 80. Os HCHs são usados na agricultura como praguicidas e em medicamentos para tratar piolhos e sarna. $\mathrm{O} \mathrm{HCH}$ pode permanecer no ar por muito tempo e ser transportado a longas distâncias. Sua absorção ocorre através das vias digestiva, respiratória e cutânea. Em seres humanos expostos ao $\mathrm{HCHs}$ observaram-se alterações no sangue, alterações em hormônios sexuais e dores de cabeça. Em animais foi observado convulsões, baixa imunidade e alterações hepáticas e renais (ATSDR, 2008). 
<smiles>Cl[C@H]1[C@H](Cl)[C@H](Cl)[C@@H](Cl)[C@@H](Cl)[C@H]1Cl</smiles>

$\alpha-\mathrm{HCH}$<smiles>Cl[C@H]1[C@H](Cl)[C@H](Cl)[C@@H](Cl)[C@@H](Cl)[C@H]1Cl</smiles>

$\beta-\mathrm{HCH}$<smiles>Cl[C@H]1[C@H](Cl)[C@H](Cl)[C@@H](Cl)[C@@H](Cl)[C@H]1Cl</smiles>

$\delta-\mathrm{HCH}$<smiles>Cl[C@H]1[C@H](Cl)[C@H](Cl)[C@@H](Cl)[C@@H](Cl)[C@H]1Cl</smiles>

$\gamma-\mathrm{HCH}$

Figura 03. Isômeros do hexaclorociclohexano (HCH).

\subsubsection{Ciclodienos}

Entre os pesticidas ciclodienos encontram-se endrin, aldrin, dieldrin, heptacloro, heptaclor epóxido, clordano, entre outros (Figuras 4,5 e 6).

$\mathrm{O}$ aldrin tem ação inseticida e é rapidamente metabolizado em dieldrin. Foi muito utilizado na agricultura durante os anos de 50 e 70 , porém a partir da década de 70 muitos países restringiram ou proibiram o seu uso. A exposição ocorre geralmente através de alimentos contaminados, ingestão de água e através da via respiratória, causando danos ao sistema nervoso central e ao fígado (NETO, 2002).

O endrin foi preparado pela conversão epoxidativa do isodrin com ácido peracético. Foi utilizado como inseticida, rodenticida e avicida. As principais vias de introdução do endrin no organismo é através de alimentos contaminados (ASSUMPÇÃO, 2002).

O heptacloro é um inseticida muito utilizado no controle de pragas do solo, de sementes e em insetos domésticos. Pode ser absorvido por via cutânea, respiratória, gastrintestinal e mucosa ocular. $\mathrm{O}$ heptacloro epóxido é o principal produto de biotransformação do heptacloro e é rapidamente formado. Pode causar disfunção reprodutiva e endócrina e câncer de bexiga (LIMA, 2002).

O clordano é um inseticida que entra no ambiente através da aplicação direta na agricultura, jardinagem e controle de cupins. É absorvido pelas vias cutâneas, respiratória e 
digestiva, podendo causar câncer, doenças do fígado e do sangue, efeitos neurológicos, cardiovasculares, respiratórios, gástricos e renais (OLIVEIRA, 2002).

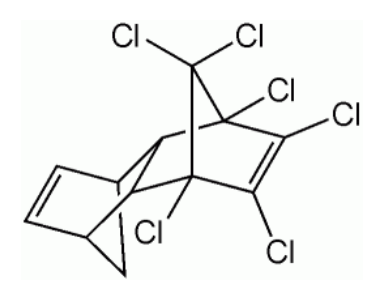

Aldrin

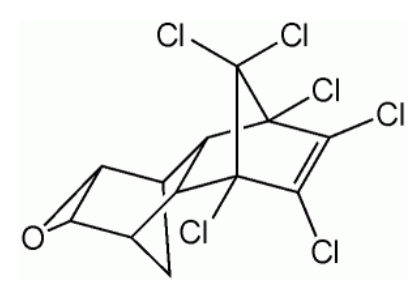

Dieldrin

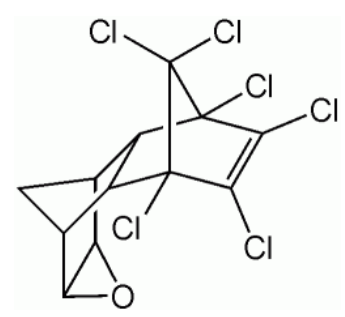

Endrin

Figura 04. Estrutura química do aldrin, dieldrin, endrin.

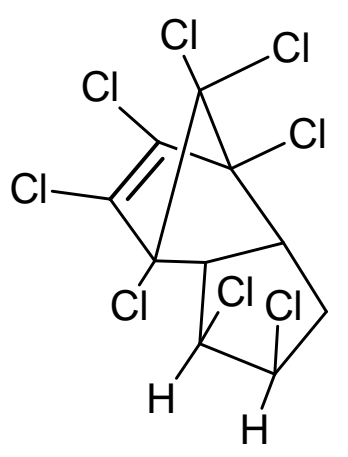

Cis-Clordano<smiles>ClC1=C(Cl)C2(Cl)C3CC4(Cl)C(Cl)C(Cl)(C3(Cl)C1(Cl)Cl)C42Cl</smiles>

Trans-Clordano

Figura 05. Formas cis e trans do Clordano. 


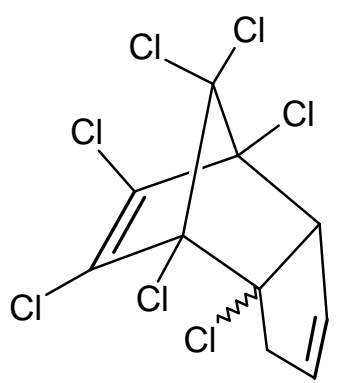

Heptacloro

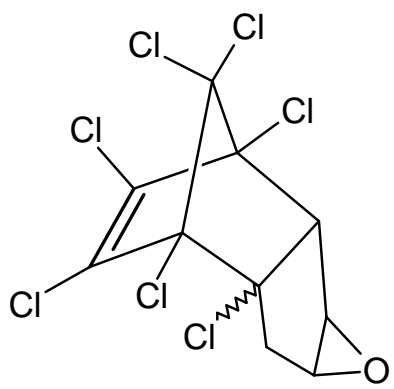

Heptacloro epóxido

Figura 06. Estrutura química do Heptacloro e Heptacloro epóxido.

\subsubsection{Mirex}

O mirex foi sintetizado em 1946 mas seu uso em formulações como agrotóxico só aconteceu em 1955, sendo comercialmente disponibilizado a partir de 1958 (Figura 7). Foi usado como inseticida em aplicações agrícolas, no controle de cupim e formigas, e como retardante de chamas. O mirex grau técnico não é produzido comercialmente nos EUA desde 1967 e os inseticidas contendo a substância foram produzidas até 1975 . Seu uso foi proibido no Brasil em 1993. A contaminação do mirex no ambiente tem acontecido pelos efluentes das instalações industriais e dos locais onde o produto foi utilizado como aditivo nos polímeros para retardante de chama, assim como dos pontos de aplicação onde foi usado como inseticida. Os alimentos são, provavelmente, a principal via de ingresso do mirex na população em geral. O pescado, os animais selvagens e a carne constituem as fontes mais importantes. A absorção ocorre pelo trato digestivo. A exposição ao mirex pode causar câncer no fígado, lesões no rins, olhos e tireóide (FERNÍCOLA, 2002). 


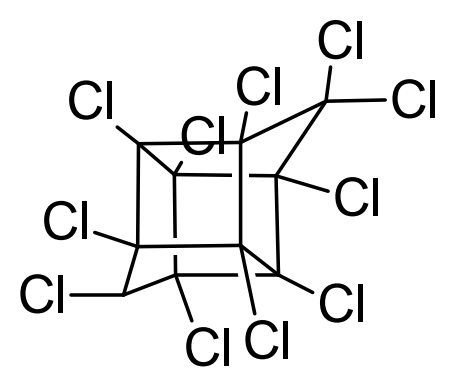

Figura 07. Mirex.

\subsubsection{Bifenilos policlorados}

Os bifenilos policlorados (PCBs) correspondem a uma classe de compostos caracterizados por uma estrutura com dois anéis benzênicos unidos por uma ligação química no átomo de carbono de cada anel, contendo 1 a 10 átomos de cloro (SALGADO, 2002) (Figura 8).

Existem 209 possíveis congêneres das PCBs, em razão das várias combinações do número de substituições de hidrogênio pelo cloro e de suas posições na molécula bifenila.

Foram sintetizados inicialmente em 1929 nos Estados Unidos, pela Monsanto Comparation e em 1966 foram reconhecidos como contaminantes ambientais devido à detecção de PCBs em amostras de animais selvagens (SALGADO, 2002).

Os PCBs produzidos comercialmente são conhecidas pelos nomes Aroclor, Askarel, Pyranol, Pyroclor, Therminol (USA), Phenochlor, Pyralene (França), Clophen, Elaol (Alemanha), Kanechlor, Santotherm (Japão), Fenchlor, Apiroli (Itália), Sovol (Rússia) e Ascarel (Brasil).

Os PCBs apresentam resistência ao fogo, baixa condutividade elétrica, alta condutividade térmica e baixa solubilidade. Os congêneres com maior o número de cloros são mais lipofílicos (WHO, 2000). 
Não se tem registro da produção de PCBs no Brasil, sendo todo produto importado principalmente dos Estados Unidos e Alemanha. A Portaria Interministerial 19, de 2 de janeiro de 1981, proibiu a fabricação, comercialização e uso de PCBs em todo território nacional.

Estima-se que devido ao grande emprego de PCBs a produção mundial acumulada foi de aproximadamente 1.200.000 toneladas. Deste total, cerca de $60 \%$ foi utilizado em transformadores e capacitores, $15 \%$ para fluidos de transferência de calor e $25 \%$ como aditivos na formulação de plastificantes, tintas, adesivos e pesticidas. Estima-se que aproximadamente 300.000 toneladas entraram para o ambiente desde 1920 e que grande parte do restante ainda está em uso, principalmente em equipamentos eletro-eletrônicos antigos (PENTEADO et al, 2001).

Devido as características físico-químicas, os organoclorados são absorvidos pelos organismos através da alimentação (membrana do trato gastrointestinal), respiração (brânquias e pulmões) e absorção (pele). Após a absorção esses compostos são rapidamente distribuídos para vários tecidos acumulando-se principalmente naqueles com alto teor de lipídios, estabelecendo-se um fluxo entre tecidos e sangue (TORDOIR \& VAN SITTERT, 1994).

A falta de uma via eficiente para a degradação dos compostos organoclorados, combinando com sua hidrofobicidade, tem levado a seu acúmulo em aves marinhas, peixes e outros organismos vivos (BAIRD, 2002), podendo sofrer um processo de bioacumulação e biomagnificação ao longo da cadeia alimentar.

Entre organismos mais suscetíveis às ações dos organoclorados encontram-se as tartarugas marinhas, principalmente espécies como a tartaruga verde Chelonia mydas que tem a sua ocorrência associada às regiões costeiras, local onde ocorre a maior incidência e acúmulo de contaminantes. 


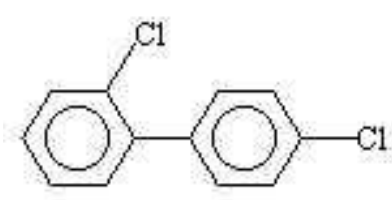

PCB8

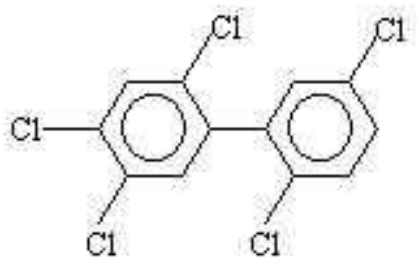

PCB101

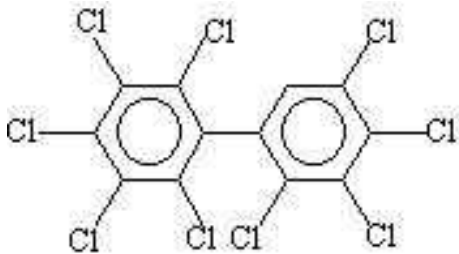

PCB195

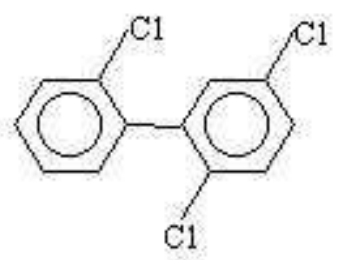

PCB18<smiles>Clc1ccc(-c2ccc(Cl)c(Cl)c2Cl)c(Cl)c1Cl</smiles>

PCB128<smiles>Clc1ccc(-c2c(Cl)c(Cl)c(Cl)c(Cl)c2Cl)c(Cl)c1Cl</smiles>

РCB206

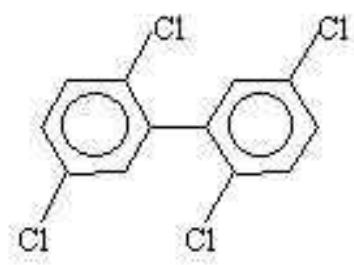

PCB52

PCB180<smiles>Clc1c(Cl)c(Cl)c(-c2c(Cl)c(Cl)c(Cl)c(Cl)c2Cl)c(Cl)c1Cl</smiles>

PCB209

Figura 08. Bifenilos policlorados.

\subsection{Tartarugas Marinhas}

Atualmente, existem sete espécies de tartarugas marinhas, agrupadas em duas famílias:

Dermochelyidae representada pela espécie Dermochelys coriacea e das Cheloniidae representada pelas espécies Caretta caretta, Eretmochelys imbricata, Chelonia mydas, 
Lepidochelys olivacea e Dermochelys coriacea. A Lepidochelys Kempii e Natator depressus, sendo que três espécies tem distribuições restritas: Natator depressus no norte da Austrália, Lepidochelys kempii no Golfo do México e Atlântico Norte (TAMAR - IBAMA, 2005). A Chelonia agassizii, que ocorre no Pacifico Leste, é reconhecida por alguns pesquisadores como espécie independente, porém, pesquisas recentes sobre sua morfologia, composição bioquímica e genética apresentam resultados que a consideram como parte da espécie Chelonia mydas (MEYLAN \& MEYLAN, 2000). As tartarugas marinhas são quelônios migradores em potencial, que buscam áreas propícias para a reprodução, alimentação e descanso (LIMA \& EVANGELISTA, 1997). As espécies que ocorrem no Brasil (C. caretta, E. imbricata, C. mydas, L. olivacea, D. coriacea) desovam no continente ou ilhas oceânicas das regiões nordeste e sudeste. Fora da estação reprodutiva adultos e indivíduos juvenis em vários estágios de desenvolvimento podem ser encontradas ao longo de quase todo o litoral, especialmente nas áreas de alimentação (MARCOVALDI \& MARCOVALDI, 1999; GALLO et al., 2000; MARCOVALDI et al., 2000).

\subsubsection{Chelonia mydas}

A identificação dessa espécie é possível analisando-se estruturas morfológicas da carapaça, do plastrão e da cabeça (Figuras 09 e 10).

A carapaça dessa espécie apresenta coloração café nos indivíduos imaturos e muita variação nos adultos, sendo geralmente café, amarelo creme e marrom manchado. A forma é oval e a margem ocasionalmente ondulada. Na carapaça possui 4 pares de placas laterais, sendo que as placas são justapostas. O plastrão possui cor branca nos indivíduos imaturos e amarelada nos adultos. A cabeça possui forma arredondada com largura de até $15 \mathrm{~cm}$, um par de escamas pré-frontais e quatro pares de escamas pós-orbitais (PRITCHARD \& MORTIMER, 2000) (Figura 11). 


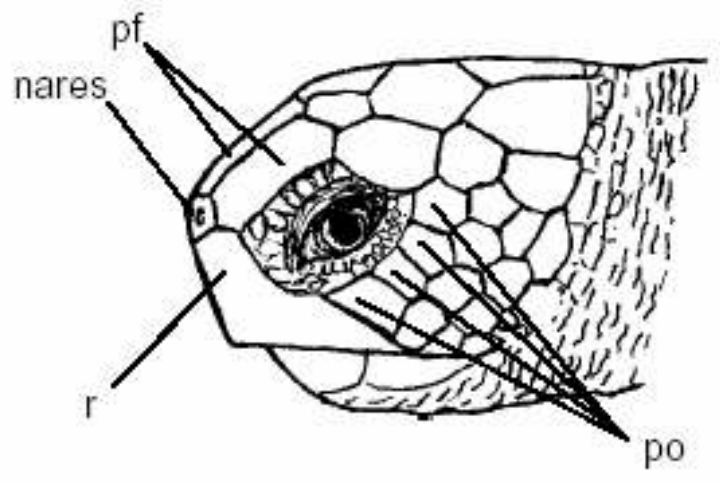

Figura 09. Estruturas da cabeça importantes para identificação da espécie Chelonia mydas. Legenda - pf: escudos pré-frontais; po: escudos pós-orbitais; nares: narinas; r: ranfoteca Fonte: Pritchard e Mortimer (2000).

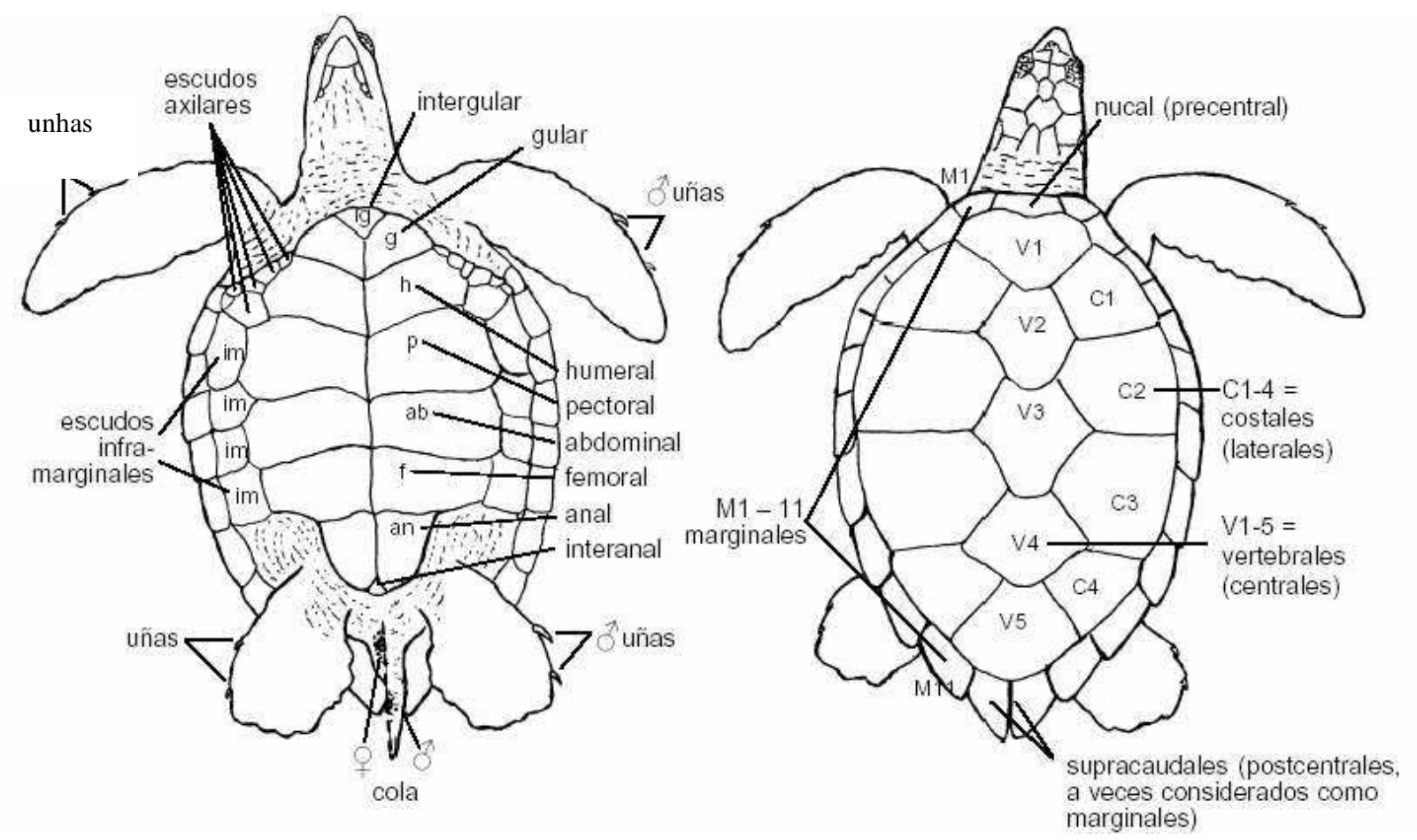

Figura 10. Estruturas morfológicas externas da carapaça e do plastrão de uma tartaruga marinha.

Fonte: Pritchard e Mortimer (2000) 


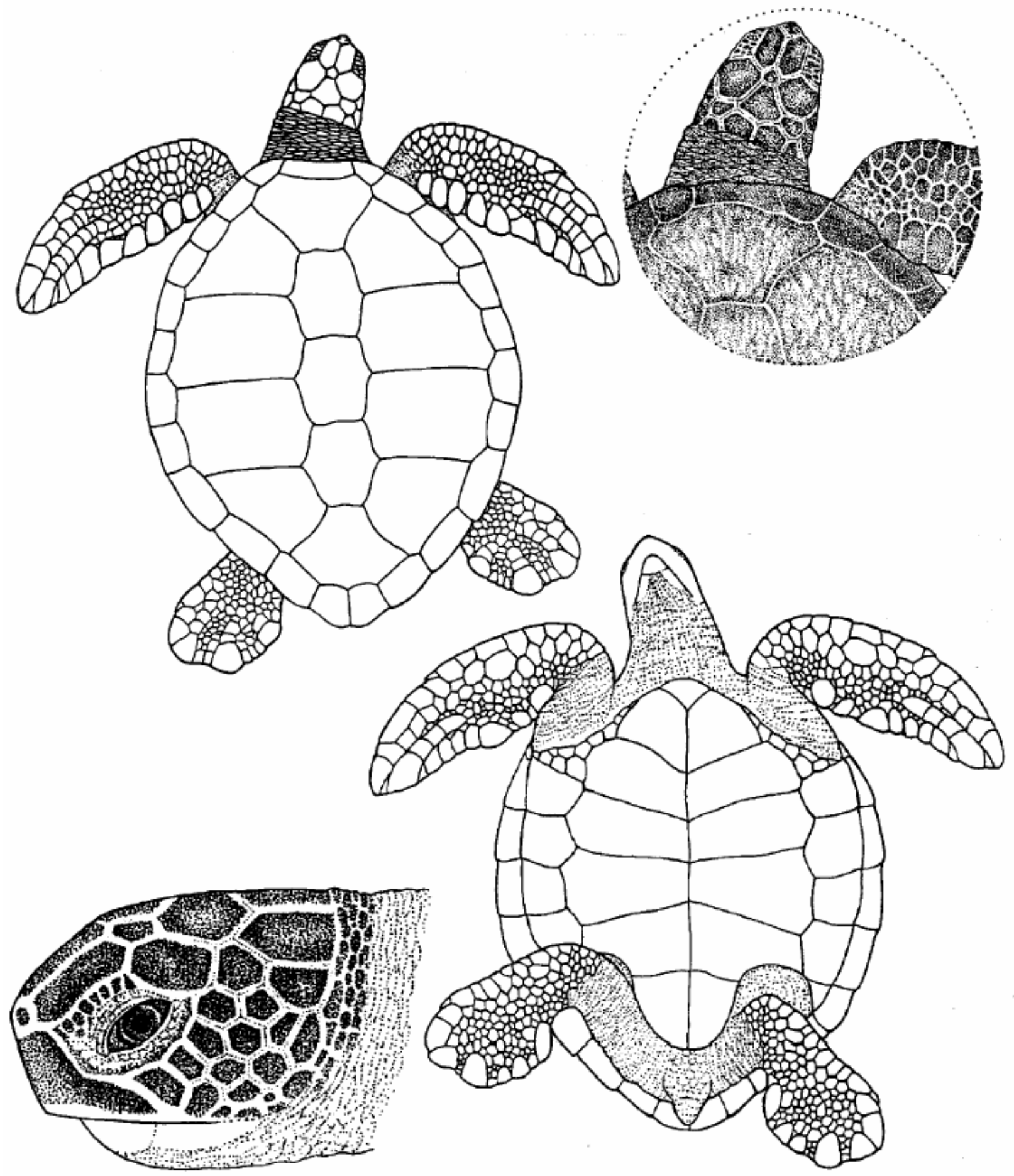

Figura 11. Distribuição das escamas da carapaça, do plastrão e da cabeça da espécie Chelonia mydas.

Fonte: Pritchard e Mortimer (2000). 
Tem uma ampla distribuição, ocorrendo nos mares tropicais e subtropicais, em águas costeiras e ao redor das ilhas, sendo rara a ocorrência em águas temperadas (FAO, 1990). As maiores colônias nidificam em praias da Costa Rica, do Suriname, da Austrália e da Nova Caledônia, e em áreas oceânicas remotas como a ilha de Ascensão. No Brasil alimentam-se em toda costa brasileira. As ilhas oceânicas são as principais áreas de desova desta espécie: Ilha de Trindade/ES, Atol das Rocas/RN e Fernando de Noronha/PE. As áreas de alimentação de juvenis desta espécie estão espalhadas ao longo da costa brasileira e nas ilhas oceânicas (TAMAR-IBAMA, 2005).

As C. mydas são animais tipicamente solitários, mas podem ser encontradas em agregações em locais de alimentação, como águas rasas e abundância de algas. Possuem comportamento migratório entre as áreas de alimentação e de reprodução, na época de reprodução, as fêmeas adultas deixam as suas áreas de alimentação e migram até a praia onde nasceram para realizarem as posturas, regressando posteriormente às áreas de alimentação. Os juvenis e sub-adultos de muitas populações residem em áreas de alimentação. Algumas tartarugas realizam migrações de mais de $2.200 \mathrm{Km}$ da área de desova até a área de alimentação (FAO, 1990).

Segundo SAZIMA \& SAZIMA (1983) e MORTIMER (1981) as tartarugas dessa espécie se alimentam basicamente durante o dia e apresentam um comportamento de seleção de alimento, no qual as tartarugas inspecionam a vegetação durante o forrageamento, discriminando as partes a serem ingeridas, mostrando assim, que existe uma seleção de alimento.

Enquanto filhote é uma espécie onívora com tendência à carnívora, os adultos são basicamente herbívoros a partir dos $25-30 \mathrm{~cm}$ de casco (BJORNDAL, 1997). Trabalhos realizados no Brasil indicam que sua dieta baseia-se em algas, preferencialmente das espécies Ulva sp, Giggartina sp e Piconiella sp (SAZIMA \& SAZIMA, 1983, GUEBERT, 2007 \& 
REISSER, 2007). Trabalhos recentes sobre o hábito alimentar de tartarugas verdes no litoral do Paraná, apontaram a presença frequente de propágulos de mangue (Avicennia sahueriana) nos conteúdos analisados, provavelmente consequentes do hábito oportunista destas tartarugas em relação ao alimento (GUEBERT, 2004).

Segundo os critérios da Lista Vermelha de Espécies Ameaçadas do IUCN (International Union for Conservation of Nature), a espécie C. mydas está classificada como "Ameaçada".

A redução das populações de tartarugas marinhas é atribuída direta ou indiretamente à destruição do habitat devido a ação antrópica nas praias, predação de ovos, juvenis e adultos, captura acidental por redes de pesca e da poluição (WYNEKEN et al., 1988).

Altas concentrações de organoclorados foram relacionadas com problemas reprodutivos, declínio de populações e imunodepressão em diversas espécies de vertebrados marinhos.

Devido ao longo tempo de vida, as tartarugas marinhas, mesmo expostas a baixas concentrações podem, em longo prazo, ter aspectos comportamentais e morfológicos alterados. Este fato pode torná-las mais suscetíveis à predação, reduzindo suas habilidades de sobrevivência e reprodução.

Poluentes químicos também podem diminuir a resistência das tartarugas marinhas a diversos vírus facilitando sua proliferação, pois os estresses causados por estes compostos podem resultar na redução da energia disponível para processos fisiológicos básicos causando alterações na imunidade celular aumentando a suscetibilidade a agentes infecciosos (AGUIRRE et al., 1994).

O papiloma cutâneo, fibroma ou fibropapiloma são tipos de lesões, caracterizadas histologicamente por uma hiperplasia epidermal, dermal ou ambos, que acomete principalmente as tartarugas marinhas juvenis ou subadultas da espécie C. mydas dos 
principais oceanos do mundo e que tomou considerável proporção a partir da década de 80 (XAVIER \& TORRES, 2002). A fibropapilomatose é uma afecção tumoral, debilitante e potencialmente fatal para as tartarugas marinhas (BAPTISTOTTE et al, 2001). A ocorrência de fibropapilomas em C. mydas pode ser de origem viral (causada por diversos tipos de vírus: hepervírus, retrovírus, papilomavírus) derivada de situações que comprometem o sistema imunológico (HERBEST, 1994).

Alguns trabalhos indicam muitos poluentes, como os organoclorados, como possíveis imunossupressores (BALAZS \& POOLEY, 1991; HUTCHINSON \& SIMMONDS, 1991), porém devido às baixas concentrações desses compostos detectadas por AGUIRRE et al. (1994) em C. mydas não foi possível estabelecer uma relação entre os organoclorados e a ocorrência de fibropapilomas.

Todavia, são poucos os estudos que reportam a ocorrência desses compostos em tartarugas marinhas, como no Mar Mediterrâneo (STORELLI et al., 2007, MCKENZIE et al., 1999, CORSOLINI et al., 2000); costa do México (GARDNER et al., 2003); Costa Rica (KLEMENS et al., 2002), Oceano Atlântico Norte (RYBITSKI et al, 1995, KELLER et al., 2004, ALAVA et al.,2006). O único estudo encontrado para a costa brasileira foi realizado com ovos de Caretta caretta (BALDASSIN et al., 2002). 


\section{Objetivos}

\subsection{Objetivo geral}

Estudar a ocorrência de organoclorados (bifenilos policlorados (PCBs) e pesticidas) em diferentes tecidos da tartaruga marinha Chelonia mydas.

\subsection{Objetivos específicos}

$\Rightarrow$ Determinar as concentrações de PCBs e pesticidas organoclorados nos tecidos (adiposo, muscular, hepático e renal) de C. mydas.

$\Rightarrow$ Comparar as concentrações destes poluentes entre os diferentes tecidos.

$\Rightarrow$ Estabelecer possíveis relações entre as concentrações de PCBs e pesticidas organoclorados com exemplares de $C$. mydas com algum tipo de alteração morfológica ou fisiológica. 


\section{Material e Métodos}

\section{1. Área de Estudo}

O presente trabalho foi realizado com amostras coletadas em Ubatuba no litoral norte de São Paulo (Figura 12). Ubatuba possui 83 praias ao longo de $106 \mathrm{~km}$ de extensão, apresentando um costa bastante recortada, formando diversas baías com águas bem tranqüilas. Além disso, a cadeia montanhosa de Serra do Mar aproxima-se bastante do oceano, formando várias ilhas, ilhotas e parcéis. Esta região é reconhecida como importante área de alimentação e refúgio de tartarugas marinhas (GALLO et al, 2000).
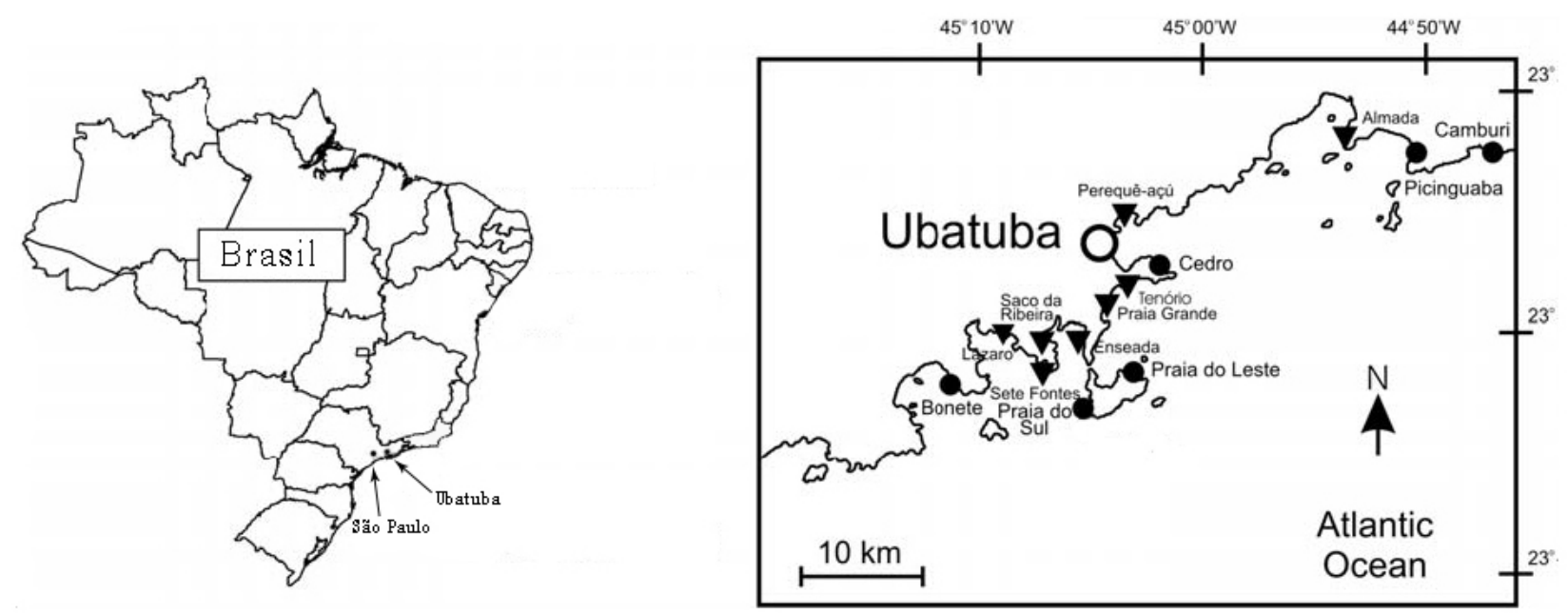

Figura 12. Mapa da região de Ubatuba, adaptado de Gallo et al. (2006).

\subsection{Amostragem}

Foram coletados 27 indivíduos da espécie Chelonia mydas na região do Ubatuba-SP, sendo 21 fêmeas e 6 machos. A biometria foi feita através das medidas de comprimento e largura da carapaça e peso (Tabela 01). 
Tabela 01. Sexo, biometria $(\mathrm{CC}=$ comprimento da carapaça, $\mathrm{LC}=$ largura da carapaça e peso $)$ e condição dos indivíduos da espécie Chelonia mydas coletadas para o presente trabalho.

\begin{tabular}{|c|c|c|c|}
\hline Identificação & Sexo & Biometria CC x LC x Peso & Condição \\
\hline CM 01 & Fêmea & $49,5 \mathrm{~cm} \times 46 \mathrm{~cm} \times 14,5 \mathrm{~kg}$ & Afogamento \\
\hline CM 02 & Fêmea & $41 \mathrm{~cm} \times 38 \mathrm{~cm} \times 6,8 \mathrm{~kg}$ & Afogamento \\
\hline CM 03 & Fêmea & $39,5 \mathrm{~cm} \times 37 \mathrm{~cm} \times 6 \mathrm{~kg}$ & Afogamento \\
\hline CM 04 & Fêmea & $37,8 \mathrm{~cm} \times 36,5 \mathrm{~cm} \times 6 \mathrm{~kg}$ & Afogamento \\
\hline CM 05 & Fêmea & $37,5 \mathrm{~cm} \times 34 \mathrm{~cm} \times 5,5 \mathrm{~kg}$ & Afogamento \\
\hline CM 06 & Fêmea & $43,5 \mathrm{~cm} \times 41 \mathrm{~cm} \times 7,5 \mathrm{~kg}$ & Debilitada \\
\hline CM 07 & Fêmea & $47 \mathrm{~cm} \times 43 \mathrm{~cm} \times 9,5 \mathrm{~kg}$ & Debilitada \\
\hline CM 08 & Fêmea & $40 \mathrm{~cm} \times 36,5 \mathrm{~cm} \times 7 \mathrm{~kg}$ & Afogamento \\
\hline CM 09 & Fêmea & $36,5 \mathrm{~cm} \times 33 \mathrm{~cm} \times 5 \mathrm{~kg}$ & Indeterminada \\
\hline CM 10 & Fêmea & $41,2 \mathrm{~cm} \times 36,7 \mathrm{~cm} \times 8,5 \mathrm{~kg}$ & Afogamento \\
\hline CM 11 & Fêmea & $45 \mathrm{~cm} \times 41 \mathrm{~cm} \times 7 \mathrm{~kg}$ & Afogamento \\
\hline CM 12 & Fêmea & $34,5 \mathrm{~cm} \times 37,5 \mathrm{~cm} \times 11 \mathrm{~kg}$ & Afogamento \\
\hline CM 13 & Fêmea & $58 \mathrm{~cm} \times 52 \mathrm{~cm} \times 22 \mathrm{~kg}$ & Afogamento \\
\hline CM 14 & Fêmea & $48,5 \mathrm{~m} \times 43 \mathrm{~cm} \times 12,5 \mathrm{~kg}$ & Afogamento \\
\hline CM 15 & Fêmea & $41,6 \mathrm{~cm} \times 37 \mathrm{~cm} \times 4,5 \mathrm{~kg}$ & Indeterminada \\
\hline CM 16 & Macho & $42 \mathrm{~cm} \times 38 \mathrm{~cm} \times 7,5 \mathrm{~kg}$ & Afogamento \\
\hline CM 17 & Fêmea & $41 \mathrm{~cm} \times 38 \mathrm{~cm} \times 5 \mathrm{~kg}$ & Lesões no intestino \\
\hline CM 18 & Fêmea & $39 \mathrm{~cm} \times 36,5 \mathrm{~cm} \times 6 \mathrm{~kg}$ & Debilitada/magra \\
\hline CM 19 & Fêmea & $35 \mathrm{~cm} \times 33,5 \mathrm{~cm} \times 4 \mathrm{~kg}$ & Debilitada \\
\hline CM 20 & Femêa & $40 \mathrm{~cm} \times 38 \mathrm{~cm} \times 7 \mathrm{~kg}$ & Afogamento \\
\hline CM 21 & Macho & $37,5 \mathrm{~cm} \times 33 \mathrm{~cm} \times 4 \mathrm{~kg}$ & Obstrução I.D. \\
\hline CM 22 & Macho & $40 \mathrm{~cm} \times 38 \mathrm{~cm} \times 6,5 \mathrm{~kg}$ & Afogamento \\
\hline CM 23 & Fêmea & $38,5 \mathrm{~cm} \times 35,5 \mathrm{~cm} \times 5 \mathrm{Kg}$ & Debilitada \\
\hline CM 24 & Macho & $36,5 \mathrm{~cm} \times 34 \mathrm{~cm} \times 4 \mathrm{~kg}$ & Obstrução \\
\hline CM 25 & Fêmea & $42,5 \mathrm{~cm} \times 38,8 \mathrm{~cm} \times 9 \mathrm{~kg}$ & Afogamento \\
\hline CM 26 & Macho & $35 \mathrm{~cm} \times 32 \mathrm{~cm} \times 5 \mathrm{~kg}$ & Afogamento \\
\hline CM 27 & Macho & $38,3 \mathrm{~cm} \times 35,5 \mathrm{~cm} \times 7,5 \mathrm{~kg}$ & Afogamento \\
\hline
\end{tabular}

Estes exemplares foram coletados mortos em praias ou capturados incidentalmente em redes de pesca e levados à base do Projeto Tamar - Ubatuba onde foram realizadas as necropsias. Foram coletadas amostras de tecidos adiposo, muscular, renal e hepático. Todas as amostras foram armazenadas separadamente em papel alumínio, identificadas e congeladas.

A licença de coleta e transporte de material biológico foi solicitada junto ao Instituto Brasileiro do Meio Ambiente e dos Recursos Naturais Renováveis - IBAMA, já que a espécie estudada neste trabalho pertence à fauna brasileira e está classificada como vulnerável na lista de espécies ameaçadas do IBAMA. A autorização foi concedida com validade até 12/11/2008. 


\subsection{Análises}

As análises para determinação de organoclorados foram realizadas no Laboratório de Química Orgânica marinha (Lab-QOM) do Instituto Oceanográfico da Universidade de São Paulo (IOUSP). Utilizou-se a metodologia já otimizada no laboratório para análise de PCBs e pesticidas em tecidos, baseada em YOGUI (2002) (Figura 13).

\subsubsection{Cuidados analíticos}

Toda a vidraria utilizada foi previamente lavada com detergente e enxaguada em água corrente. Depois de seca foi coberta com alumínio e levada a mufla durante 4 horas a $400{ }^{\circ} \mathrm{C}$. Vidrarias volumétricas que não podiam ser mufladas foram enxaguadas com diclorometano e n-hexano antes do uso.

Todos os solventes que foram utilizados era para análise de resíduos a fim de garantir o alto grau de pureza.

\subsubsection{Soluções Padrões}

As soluções de organoclorados utilizadas foram adquiridas do laboratório internacional AccuStandard (EUA). A partir desses padrões certificados preparou-se três tipos de soluções: as misturas com padrões externos, sendo uma para PCBs e uma para pesticidas, a solução de padrões surrogate e o padrão interno (PI).

A mistura de PCBs continha 52 congêneres, com compostos contendo de 2 a 10 átomos de cloro. A mistura de pesticidas continha os DDTs e seus metabólitos ( $o, p$ '-DDD; $p, p^{\prime}$-DDD; $\left.o, p^{\prime}-\mathrm{DDE} ; p, p^{\prime}-\mathrm{DDE} ; \quad o, p^{\prime}-\mathrm{DDT} ; \quad p, p^{\prime}-\mathrm{DDT}\right), \mathrm{HCHs}$ (alfa-HCH; beta-HCH; gama-HCH (Lindano); delta-HCH; clordanas (cis-clordana; trans-clordana; heptaclor; heptaclor epóxido), entre outros. Ambas as misturas dos organoclorados possuíam concentração de $1,0 \mathrm{ng} \mu \mathrm{l}^{-1}$. 
A solução de surrogate continha o PCB 103 e o PCB 198 e a solução de Padrão interno (PICG) continha o composto TCMX (2,3,5,6-tetracloro-m-xileno), todos em concentração de $1,0 \mathrm{ng} \mu \mathrm{l}^{-1}$.

\subsubsection{Curva analítica}

A curva analítica para os PCBs e pesticidas foi construída com nove pontos, com as seguintes concentrações: $1,5,10,20,50,80,100,150$ e $200 \mathrm{pg} \mathrm{l}^{-1}$. Para as duas curvas foi considerado um coeficiente de correlação maior ou igual a 0,995 .

A identificação dos pesticidas foi feita em relação aos tempos de retenção dos picos no cromatograma. Para a identificação dos PCBs além dos tempos de retenção, também foram utilizados os espectros de massas. A quantificação de todos os compostos foi feita em relação à área dos picos dos padrões.

As curvas foram verificadas periodicamente recalculando-se seus próprios pontos. A curva estaria boa para o uso se apresentasse um fator de resposta com menos de $25 \%$ de variação.

\subsubsection{Preparação das amostras para análise de organoclorados}

Para o controle de qualidade e o limite de detecção foram utilizados para cada amostra 0,25 g de fígado da espécie Chelonia mydas. Para análise das amostras foram utilizados $0,25 \mathrm{~g}$ de gordura, fígado e rim e $5 \mathrm{~g}$ de músculo. As porções de amostras utilizadas foram cortadas da parte interna da amostra original para evitar contaminações que poderiam ter ocorrido na superfície. As amostras foram pesadas em papel alumínio utilizando-se uma balança analítica.

\subsubsection{Extração}

As amostras de tecidos foram maceradas com cerca de $6 \mathrm{~g}$ de sulfato de sódio anidro. Foram adicionados em cada uma das amostras e brancos, $100 \mu 1$ de cada um dos padrões 
internos (PCB 103 e PCB 198). Na matriz fortificada e no branco fortificado foram adicionados também $50 \mu \mathrm{l}$ de cada uma das misturas contendo os compostos a serem analisados (PCBs e pesticidas) com a concentração de $\operatorname{lng} \mu \mathrm{l}^{-1}$. Para o limite de detecção foram adicionados $100 \mu \mathrm{l}$ de cada uma das misturas contendo os compostos a serem

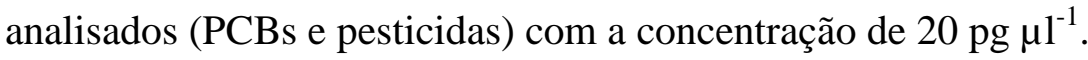

As amostras foram extraídas em Soxhlet por $8 \mathrm{~h}$ com $80 \mathrm{ml}$ de n-hexano e 100 diclorometano (1:1). O extrato foi concentrado a $1,0 \mathrm{ml}$, de onde se retirou $0,1 \mathrm{ml}$ para determinação de lipídios.

\subsubsection{Tratamento Ácido}

O tratamento ácido é utilizado para a purificação dos extratos gordurosos. Diversos grupos de compostos organoclorados são estáveis sob tratamento ácido, como PCBs, DDTs, HCHs, entre outros, entretanto, alguns compostos são destruídos e não podem ser quantificados, como endrin, isodrin, dieldrin, metoxicloro, $\alpha$-clordana, heptacloro epóxido A e B, endosulfan I e II.

A reação ocorreu entre $0,9 \mathrm{~mL}$ do extrato e $2,0 \mathrm{~mL}$ de ácido sulfúrico concentrado (96\%) e agitados durante 1 minuto para garantir a hidrólise completa dos lipídios. Após esse período, os tubos de reação foram colocados em centrífuga Excelsa II (modelo 206 BL) por 60 minutos, com $2500 \mathrm{rpm}$, no formato de 16 X $15 \mathrm{ml}$.

Após a separação, a fase hexânica foi separada e lavada duas vezes com $8 \mathrm{ml}$ de água destilada pré-extraída 5x com n-hexano agitando-se essa mistura heterogênea por 1 minuto. Essa etapa é importante para remover resíduos de ácido dissolvidos no n-hexano (que podem danificar a coluna capilar do cromatógrafo), bem como compostos polares resultantes do tratamento ácido. Foram adicionados ao extrato concentrado $90 \mu \mathrm{l}$ de padrão interno (TCMX) que foi completado a $0,9 \mathrm{~mL}$. 


\subsubsection{Estimativa do peso lipídico}

O peso lipídico foi calculado separando-se $0,1 \mathrm{ml}$ do volume total concentrado. Este volume foi colocado em pequenos frascos de vidro, previamente pesados. Após a total evaporação, cada frasco foi novamente pesado e a diferença entre a pesagem inicial e a pesagem após a adição e evaporação da alíquota foi utilizada no cálculo da percentagem de lipídios. A equação utilizada foi:

$$
\text { \%lipídios = resíduo }(\mathrm{mg}) / \text { Massa extraída }
$$

\subsubsection{Estimativa do peso seco}

Aproximadamente $1 \mathrm{~g}$ de amostra foi seco em uma estufa à temperatura de $70^{\circ} \mathrm{C}$ aproximadamente durante 48 horas. Utilizando o valor obtido através da repesagem do material, calculou-se o peso seco da amostra, com a seguinte equação:

Peso seco $=\frac{\text { peso do frasco com amostra }(\mathrm{mg})-\text { peso do frasco vazio }(\mathrm{mg})}{\text { peso do frasco com amostra }(\mathrm{mg})-\text { peso do frasco }(\mathrm{mg})}$ 


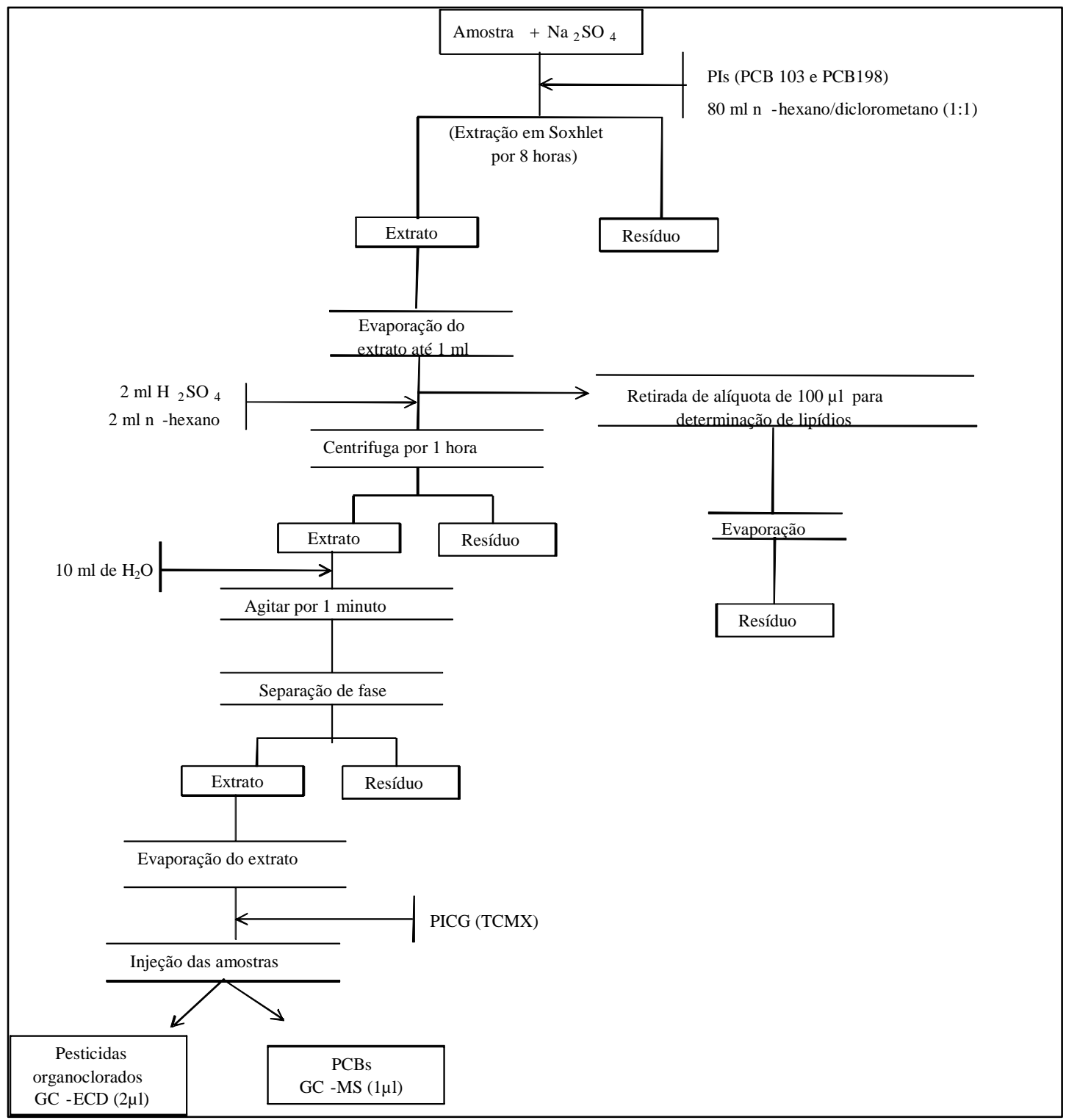

Figura 13. Fluxograma do experimento analítico

\subsubsection{Análise dos compostos por cromatografia em fase gasosa (GC)}

Para a análise PCBs os extratos das amostras foram injetadas em um cromatógrafo a gás acoplado a um espectrômetro de massas, $5973 \mathrm{~N}$ da Agilent Technologies com impacto de elétrons (EI). O equipamento operou no modo de monitoramento seletivo de íons (SIM) (70eV). A coluna utilizada foi a HP 5MS da Agilent com $30 \mathrm{~m}$ de comprimento, 0,25 mm de diâmetro interno e $0,25 \mu \mathrm{m}$ de espessura de filme de $5 \%$ fenil metilsiloxana. 
A rampa de temperatura utilizada na separação dos $\mathrm{PCBs}$ teve início em $75^{\circ} \mathrm{C}$, permanecendo por $3 \mathrm{~min}$, quando começou a subir a uma taxa de $15{ }^{\circ} \mathrm{C} \min ^{-1}$ até atingir 150 ${ }^{\circ} \mathrm{C}$, depois subiu até $260{ }^{\circ} \mathrm{C}$ a uma taxa de $2{ }^{\circ} \mathrm{C} \min ^{-1}$ e então subiu até $300{ }^{\circ} \mathrm{C}$ a uma taxa de 20 ${ }^{\circ} \mathrm{C} \min ^{-1}$, mantendo-se estável nessa temperatura por $10 \mathrm{~min}$, totalizando $66 \mathrm{~min}$. O gás de arraste utilizado foi o hélio com fluxo constante de $1,1 \mathrm{ml} \mathrm{min}^{-1}$. A temperatura do injetor foi de $270^{\circ} \mathrm{C}$. Temperatura da interface foi mantida a $280^{\circ} \mathrm{C}$, da fonte a $300^{\circ} \mathrm{C}$ e do quadrupolo a $200^{\circ} \mathrm{C}$. O volume injetado foi de $1 \mu \mathrm{L}$ no modo sem divisão de fluxo (splitless).

As análises de pesticidas nas amostras foram feitas em um cromatógrafo a gás acoplado a detector de captura de elétrons GC ECD 6890 da Agilent Technologies. O gás de arraste usado foi o hidrogênio com pressão constante de 13,00 psi. A coluna utilizada foi a HP-5MS da Agilent com $30 \mathrm{~m}$ de comprimento, 0,25 mm de diâmetro interno e 0,5 $\mu \mathrm{m}$ de espessura de filme de 5\% fenil metilsiloxana. A rampa utilizada na separação dos compostos permaneceu em $70^{\circ} \mathrm{C}$ por $1 \mathrm{~min}$, elevou-se a $170^{\circ} \mathrm{C}\left(40^{\circ} \mathrm{C} \min ^{-1}\right), 240^{\circ} \mathrm{C}\left(1,5^{\circ} \mathrm{C} \min ^{-1}\right)$ e então subiu até $300^{\circ} \mathrm{C}$, a $15^{\circ} \mathrm{C} \min ^{-1}$, mantendo-se estável nessa temperatura por 5 min, totalizando $61,16 \mathrm{~min}$. As temperaturas do injetor e do detector foram de $280^{\circ} \mathrm{C}$ e $320^{\circ} \mathrm{C}$, respectivamente. Nitrogênio foi utilizado como gás auxiliar (makeup) com um fluxo de $60 \mathrm{ml} \min ^{1}$. O volume injetado foi de $2 \mu \mathrm{L}$ no modo sem divisão de fluxo (splitless).

\subsubsection{Limite de detecção do método}

O limite de detecção de um método (LDM) é definido como a concentração mínima de uma substância que pode ser medida com $95 \%$ de confiança, que essa concentração é diferente de zero e pode ser determinada em uma matriz contendo o analito (Wade \& Cantillo, 1994). Nesse método, o limite de detecção foi calculado através da quantificação de uma pequena quantidade de analitos adicionados a uma matriz que não continha os compostos em estudo. $\mathrm{O}$ cálculo para determinação do limite de detecção é de três vezes o desvio padrão dessa matriz 
em sete réplicatas. Para realização do limite de detecção utilizou-se $0,25 \mathrm{~g}$ do fígado de um espécime de tartaruga verde Chelonia mydas, coletada em Cananéia, litoral sul de São Paulo.

\section{Limite de Detecção do método $($ LDM $)=3 x$ desvio padrão das 7 replicatas}

Dessa forma foi possível avaliar a influência das matrizes durante a análise, pois essas amostras, podem apresentar uma série de interferentes que influenciam na análise.

O limite de detecção variou de 1,65 a 6,01 ng. $\mathrm{g}^{-1}$ para os PCBs (Tabela 2), e para os pesticidas variaram de 2,01 a 10,22 ng. $\mathrm{g}^{-1}$ (Tabela 03).

Tabela 02. Limite de detecção do método (LDM) para PCBs em tecidos.

\begin{tabular}{cccc}
\hline Congêneres & LDM ng.g & Congêneres & LDM ng $\mathbf{~}^{\mathbf{1}}$ \\
\hline PCB8 & 1,7 & PCB128 & 2,4 \\
PCB18 & 2,9 & PCB132 & 3,6 \\
PCB28 & 2,8 & PCB138 & 5,5 \\
PCB31 & 3,1 & PCB141 & 3,3 \\
PCB33 & 3,0 & PCB149 & 1,4 \\
PCB44 & 2,5 & PCB151 & 2,1 \\
PCB49 & 2,4 & PCB153 & 6,0 \\
PCB52 & 2,9 & PCB156 & 3,1 \\
PCB56/60 & 2,8 & PCB157 & 3,8 \\
PCB66 & PCB158 & 1,6 \\
PCB70 & 2,6 & PCB167 & 2,5 \\
PCB74 & 3,3 & PCB169 & 3,4 \\
BCP77 & 1,7 & PCB170 & 2,6 \\
PCB81 & 2,8 & PCB174 & 1,7 \\
PCB87 & 1,8 & PCB177 & 2,6 \\
PCB95 & 1,8 & PCB180 & 3,8 \\
PCB97 & 3,2 & PCB183 & 2,5 \\
PCB99 & 2,0 & PCB187 & 2,0 \\
PCB101 & 1,9 & PCB189 & 2,2 \\
PCB110 & 3,2 & PCB194 & 3,4 \\
PCB105 & 4,2 & PCB195 & 4,1 \\
PCB114 & 3,3 & PCB199 & 2,4 \\
PCB118 & 1,7 & PCB203 & 2,3 \\
PCB123 & 2,6 & PCB206 & 3,7 \\
PCB126 & 2,1 & PCB209 & 2,4 \\
\hline
\end{tabular}


Tabela 03. Limite de detecção método (LDM) para Pesticidas em tecidos.

\begin{tabular}{cc}
\hline Composto & LDM ng $\mathbf{~ g}^{-1}$ \\
\hline HCB & 2,0 \\
$\alpha-\mathrm{HCH}$ & 2,1 \\
$\beta-\mathrm{HCH}$ & 6,9 \\
$\gamma-\mathrm{HCH}$ & 3,4 \\
$\delta$-HCH & 4,4 \\
Heptacloro & 3,1 \\
Oxiclordana & 6,3 \\
$\gamma$-clordana & 2,3 \\
$o, p$-DDE & 2,8 \\
$p, p$-DDE & 3,3 \\
$o, p$-DDD & 9,7 \\
$p, p$-DDD & 10,2 \\
$o, \mathrm{p}$-DDT & 9,7 \\
$p, p$-DDT & 7,6 \\
Mirex & 7,4 \\
\hline
\end{tabular}

\subsubsection{Controle de Qualidade}

Para verificar a precisão e exatidão das análises foi realizado um controle de qualidade contendo um branco, um branco fortificado, uma matriz e sua duplicata, matriz fortificada e análise do material de referência certificado.

Os critérios para o controle de qualidade de uma metodologia segundo Sericano 1998, são:

- Os padrões internos devem ser recuperados entre $50 \%$ e $120 \%$ em todas as amostras analisadas;

- O branco deve conter no máximo dois compostos com concentração maior que três vezes o limite de detecção do método;

- O branco fortificado deve conter $80 \%$ dos analitos com recuperação entre $40 \%$ e $130 \%$

- A matriz fortificada deve conter $80 \%$ dos analitos com recuperação entre $40 \%$ e $130 \%$. 
Para os organoclorados, o cálculo da recuperação do surrogate foi realizado dividindo sua concentração pela concentração do TCMX calculada em cada amostra.

O branco foi usado para determinar se as amostras foram contaminadas durante todo o processo analítico, sendo que os valores encontrados no branco foram descontados de todas as amostras. A duplicata foi usada para avaliar a homogeneidade da amostra e a precisão analítica do método, sendo que a diferença entre as duplicatas não deve ultrapassar $25 \%$. A matriz fortificada foi utilizada para verificar a eficiência do método com influência da matriz a ser analisada.

Para os organoclorados as recuperações obtidas com este método estavam dentro da faixa aceitável, conforme proposto por Sericano (1998). Para os PCBs as recuperações médias dos padrões internos PCB 103 e PCB 198 foram de 69,5\% e 83,5\%, respectivamente. A recuperação dos padrões de PCBs no branco variou entre $98 \%$ e $120 \%$ e na amostra variou entre $93 \%$ e $119 \%$ (Tabela 4). Para os pesticidas as recuperações médias dos padrões internos PCB 103 e PCB 198 foram de 70\% e 94\%, respectivamente. A recuperação dos padrões de pesticidas no branco e na amostra variou entre 65\% e 111\% (Tabela 5). Todos esses resultados evidenciam as boas condições do processo metodológico. Para a análise de PCBs e pesticidas organoclorados as recuperações do padrão interno obtidas variaram entre $57 \%$ a $92 \%$. 
Tabela 04. Recuperação (\%) dos padrões internos (PI) e dos 52 PCBs analisados para o branco fortificado e a amostra fortificada no controle de qualidade.

\begin{tabular}{|c|c|c|c|c|c|}
\hline Congênere & Branco & Amostras & Congênere & Branco & Amostras \\
\hline PCB103 (PI) & 66 & 73 & PCB126 (5Cl) & 106 & 103 \\
\hline PCB198 (PI) & 77 & 90 & PCB128 (6Cl) & 112 & 108 \\
\hline PCB8 $(2 \mathrm{Cl})$ & 106 & 97 & PCB132 (6Cl) & 120 & 117 \\
\hline PCB18 (2Cl) & 98 & 93 & PCB141 (6Cl) & 120 & 114 \\
\hline PCB28 (2Cl) & 108 & 112 & PCB149 $(6 \mathrm{Cl})$ & 110 & 107 \\
\hline PCB31 (2Cl) & 105 & 95 & PCB151 (6Cl) & 116 & 107 \\
\hline PCB33 (2Cl) & 106 & 103 & PCB153 (6Cl) & 100 & 118 \\
\hline PCB44 (4Cl) & 108 & 101 & PCB156 (6Cl) & 107 & 102 \\
\hline PCB49 (4Cl) & 107 & 99 & PCB157 (6Cl) & 109 & 106 \\
\hline PCB52 (4Cl) & 117 & 108 & PCB158 (6Cl) & 112 & 108 \\
\hline PCB70 (4Cl) & 108 & 105 & PCB167 (6Cl) & 117 & 106 \\
\hline PCB56/60(4Cl) & 105 & 101 & PCB169 (6Cl) & 118 & 118 \\
\hline PCB66 (4Cl) & 105 & 102 & PCB170 $(7 \mathrm{Cl})$ & 116 & 101 \\
\hline PCB74 (4Cl) & 105 & 105 & PCB174 (7Cl) & 116 & 108 \\
\hline PCB77 (4Cl) & 103 & 102 & PCB177 $(7 \mathrm{Cl})$ & 115 & 110 \\
\hline PCB81 (4Cl) & 104 & 103 & PCB180 (7Cl) & 120 & 108 \\
\hline PCB87 (5Cl) & 111 & 105 & PCB183 (7Cl) & 119 & 108 \\
\hline PCB95 (5Cl) & 105 & 101 & PCB187 (7Cl) & 116 & 109 \\
\hline PCB97 (5Cl) & 115 & 112 & PCB189 (7Cl) & 119 & 116 \\
\hline PCB99 (5Cl) & 112 & 106 & PCB194 (8Cl) & 89 & 101 \\
\hline PCB101 (5Cl) & 118 & 119 & PCB195 (8Cl) & 111 & 117 \\
\hline PCB105 (5Cl) & 103 & 104 & PCB199 (8Cl) & 110 & 113 \\
\hline PCB1 $10(5 \mathrm{Cl})$ & 108 & 103 & PCB203 (8Cl) & 111 & 112 \\
\hline PCB114 (5Cl) & 114 & 111 & PCB206 (9Cl) & 107 & 101 \\
\hline PCB1 $18(5 \mathrm{Cl})$ & 108 & 102 & PCB209 $(10 \mathrm{Cl})$ & 103 & 112 \\
\hline PCB123 (5Cl) & 112 & 108 & & & \\
\hline
\end{tabular}


Tabela 05.. Recuperação (\%) dos padrões internos (PI) e dos pesticidas analisados para o branco fortificado e a amostra fortificada no controle de qualidade.

\begin{tabular}{ccc}
\hline Composto & Branco & Amostras \\
\hline PCB 103 (PI) & 70 & 70 \\
PCB198 (PI) & 96 & 92 \\
HCB & 79 & 79 \\
$\alpha-\mathrm{HCH}$ & 88 & 88 \\
$\beta-\mathrm{HCH}$ & 75 & 75 \\
$\gamma$-HCH & 70 & 67 \\
$\delta$-HCH & 65 & 65 \\
Heptacloro & 89 & 88 \\
Oxiclordana & 108 & 107 \\
$\gamma$-clordana & 77 & 76 \\
op'-DDE & 84 & 83 \\
pp'-DDE & 83 & 83 \\
op'-DDD & 101 & 101 \\
pp'-DDD & 79 & 78 \\
op'-DDT & 110 & 110 \\
pp'-DDT & 83 & 81 \\
Mirex & 111 & 111 \\
\hline
\end{tabular}

\subsubsection{Material de referência certificado}

O material de referência certificado, SRM (Standard Reference Material ${ }^{\circledR}$ ) ou CRM (Certified Reference Material), deve ser utilizado por laboratórios para avaliar seus métodos analíticos e avaliar sua exatidão (WADE e CANTILLO, 1994). O material de referência é uma amostra bem caracterizada com relação aos analitos de interesse. O certificado de análise que acompanha a amostra, consta dos valores certificados e de suas incertezas (SCHANTZ et al., 1995).

Para a avaliação da metodologia desenvolvida no presente trabalho foi usado o SRM 1945 (Standard Reference Material 1945 - Organics in Whale Blubber), que é composto de um homogenizado de gordura subcutânea ("blubber") de uma baleia piloto (fêmea adulta) proveniente de encalhe em Cape Cod, Massachussets (EUA) em setembro de 1991. O SRM 
usado no presente trabalho foi obtido do NIST (National Institute of Standards and Technology) dos Estados Unidos. A quantidade de SRM utilizado nesta análise foi de 0,25 g. De acordo com o critério de aceitação em programas desenvolvidos pelo NS\&T (WADE e CANTILLO, 1994), a metodologia é considerada confiável se $80 \%$ dos compostos analisados estiverem dentro da faixa apresentada no certificado, acrescido de $\pm 35 \%$. Conforme DENOUX \& WANG (1998), o alcance da mesma distribuição estatística em repetidas análises de um SRM não é freqüentemente garantido e uma variabilidade mais ampla pode ser aceita. Todos os compostos analisados estiveram dentro da faixa adequada (Tabela 6), os cromatogramas do material de referência estão apresentados nas Figuras 14 e 15. 
Tabela 06. Resultados obtidos na análise do material de referência certificado SRM 1945.

\begin{tabular}{|c|c|c|c|c|c|c|}
\hline \multirow[b]{2}{*}{ Compostos } & \multirow{2}{*}{$\begin{array}{c}\text { Resultados } \\
\text { obtidos } \\
{\left[\text { [ ] }\left(\mathrm{ng} \mathrm{g}^{-1}\right)\right.}\end{array}$} & \multicolumn{5}{|c|}{ Resultados aceitáveis } \\
\hline & & $\begin{array}{c}\text { Valor certificado (95\%) } \\
\left(\mathrm{ng} \mathrm{g}^{-1}\right)\end{array}$ & Desvio padrão & $\begin{array}{l}\text { Fai } \\
\text { inferior }\end{array}$ & $\begin{array}{l}\text { ka aceitáve } \\
\text { superior }\end{array}$ & Avaliação \\
\hline PCB18 & 3,51 & 4,48 & 0,88 & 2,34 & 7,24 & $\mathrm{OK}$ \\
\hline PCB44 & 7,23 & 12,2 & 1,4 & 7,02 & 18,36 & OK \\
\hline PCB49 & 11,22 & 20,8 & 2,8 & 11,7 & 31,86 & OK \\
\hline PCB52 & 28,07 & 43,6 & 2,5 & 26,715 & 62,24 & OK \\
\hline PCB66 & 15,33 & 23,6 & 1,6 & 14,3 & 34,02 & OK \\
\hline РCB87 & 15,62 & 16,7 & 1,4 & 9,945 & 24,44 & OK \\
\hline РСB95 & 21,75 & 33,8 & 1,7 & 20,865 & 47,93 & OK \\
\hline РСB99 & 30,28 & 45,4 & 5,4 & 26 & 68,58 & OK \\
\hline PCB101 & 49,59 & 65,2 & 5,6 & 38,74 & 95,58 & OK \\
\hline PCB110 & 21,81 & 23,3 & 4 & 12,545 & 36,86 & OK \\
\hline PCB118 & 51,24 & 74,6 & 5,1 & 45,175 & 107,60 & OK \\
\hline PCB128 & 16,42 & 23,7 & 1,7 & 14,3 & 34,29 & OK \\
\hline PCB138 & 134,52 & 131,5 & 7,4 & 80,665 & 187,52 & OK \\
\hline PCB149 & 65,95 & 106,6 & 8,4 & 63,83 & 155,25 & $\mathrm{OK}$ \\
\hline PCB151 & 16,57 & 28,7 & 5,2 & 15,275 & 45,77 & OK \\
\hline PCB153 & 201,37 & 213 & 19 & 126,1 & 313,20 & OK \\
\hline PCB156 & 6,85 & 10,3 & 1,1 & 5,98 & 15,39 & OK \\
\hline PCB170 & 37,12 & 40,6 & 2,6 & 24,7 & 58,32 & OK \\
\hline PCB180 & 109,97 & 106,7 & 5,3 & 65,91 & 151,20 & OK \\
\hline PCB183 & 22,48 & 36,6 & 4,1 & 21,125 & 54,95 & OK \\
\hline PCB187 & 84,63 & 105,1 & 9,1 & 62,4 & 154,17 & OK \\
\hline PCB194 & 45,95 & 39,6 & 2,5 & 24,115 & 56,84 & OK \\
\hline PCB195 & 9,23 & 17,7 & 4,3 & 8,71 & 29,70 & OK \\
\hline PCB206 & 44,03 & 31,1 & 2,7 & 18,46 & 45,63 & OK \\
\hline PCB209 & 12,19 & 10,6 & 1,1 & 6,175 & 15,80 & OK \\
\hline HCB & 21,2 & 32,9 & 1,70 & 20,30 & 46,70 & OK \\
\hline$\alpha-\mathrm{HCH}$ & 9,37 & 16,2 & 3,40 & 6,09 & 21,87 & OK \\
\hline $\mathrm{\gamma}-\mathrm{HCH}$ & 5,26 & 3,3 & 0,81 & 3,42 & 4,46 & OK \\
\hline Oxiclordana & 17,40 & 19,8 & 1,90 & 11,31 & 26,73 & OK \\
\hline Mirex & 31,10 & 28,9 & 2,80 & 20,22 & 39,02 & OK \\
\hline op'-DDE & 17,26 & 12,28 & 0,87 & 11,22 & 16,58 & OK \\
\hline pp'-DDE & 330,09 & 445 & 37,0 & 214,56 & 600,75 & OK \\
\hline op'-DDD & 22,92 & 18,1 & 2,80 & 14,90 & 24,44 & OK \\
\hline pp'-DDD & 152,63 & 133 & 10,0 & 99,21 & 179,55 & OK \\
\hline op'-DDT & 69,09 & 106 & 14,0 & 44,91 & 143,10 & OK \\
\hline pp'-DDT & 153,90 & 245 & 15,0 & 100,04 & 330,75 & OK \\
\hline
\end{tabular}




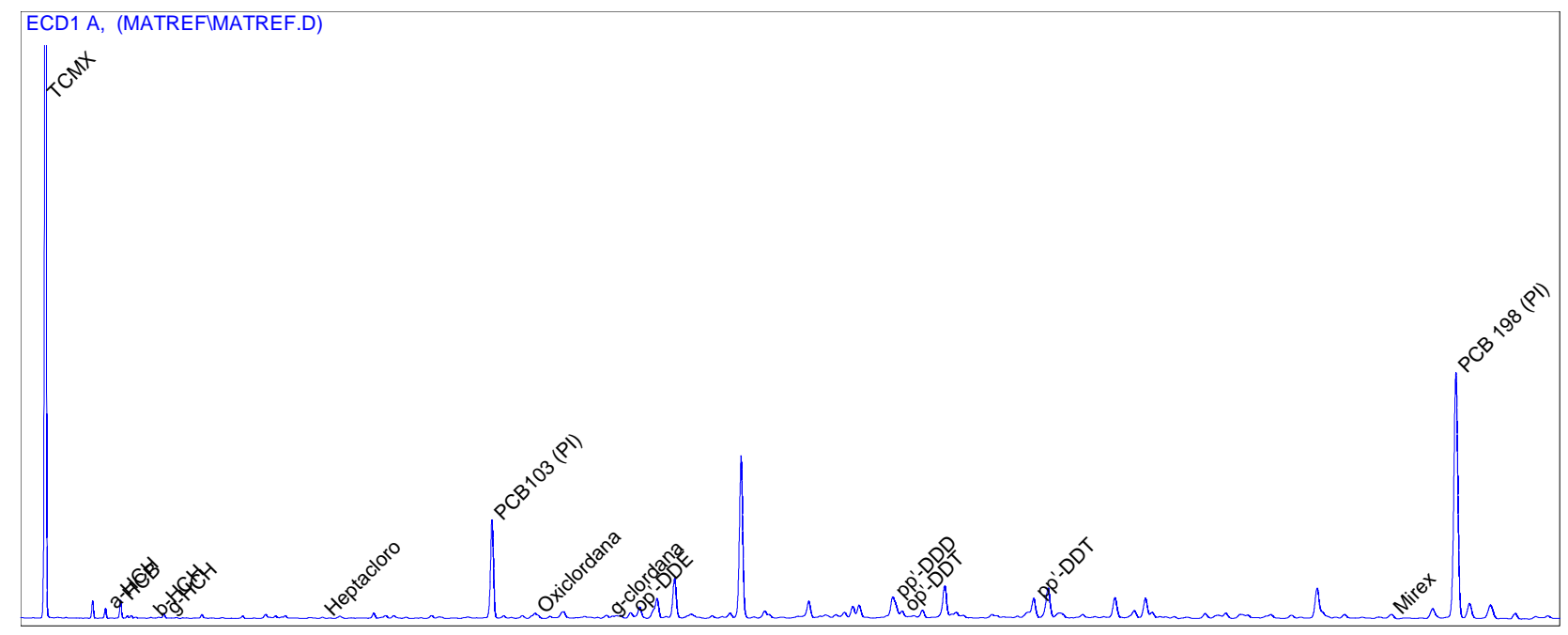

Figura 14. Cromatograma obtido para o material de referência no GC-ECD

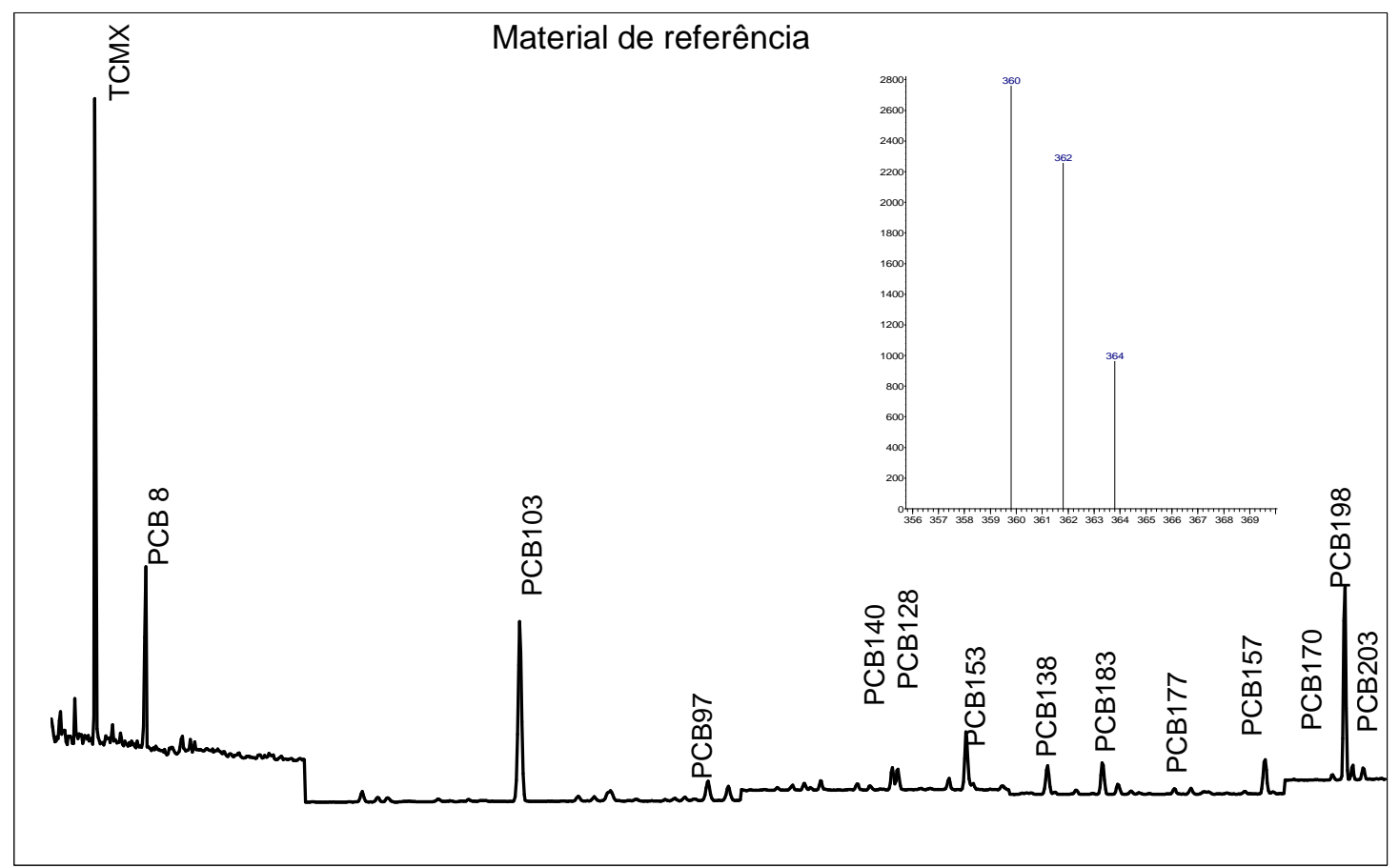

Figura 15. Cromatograma e exemplo do espectro de massas do PCB 153 obtidos para o material de referência no GC-MS. 


\section{Resultados e Discussão}

Os resultados das análises dos compostos organoclorados detectados nas amostras dos 27 espécimes de Chelonia mydas estão apresentados na Tabela 07 em ng.g ${ }^{-1}$ em peso úmido. Os PCBs foram os únicos compostos detectados nas 27 amostras de Chelonia mydas, demonstrando assim a sua ampla distribuição pelos ambientes costeiros. As concentrações de PCBs totais em peso úmido (soma dos 52 congêneres analisados) variaram de <1,6 - 48,9 ng. $\mathrm{g}^{-1}$ na gordura, $<1,6-17,4 \mathrm{ng} \cdot \mathrm{g}^{-1}$ no fígado e $<1,6-9,2 \mathrm{ng} \cdot \mathrm{g}^{-1}$ no rim. As concentrações dos PCBs nos machos variaram de $<1,6$ a 26,0 ng.g ${ }^{-1}$ e nas fêmeas de <1,6 a 48.9 ng.g ${ }^{-1}$.

A ausência de pesticidas organoclorados nas amostras estudadas deve-se, possivelmente, às características não agrícolas do litoral norte do estado de São Paulo. Os problemas ambientais existentes nessa região estão associados à intensa atividade turística durante o período de verão e a presença do Porto de São Sebastião e o Duto e Terminais Centro Sul (DTCS). Nessa região não são encontradas grandes indústrias, e não foi relatado o uso de agrotóxicos clorados na literatura. 
Tabela 07. Concentração de PCBs (ng.g ${ }^{-1} /$ peso úmido) nas amostras de gordura, fígado e rim de fêmeas e machos da espécie $C$. mydas.

\begin{tabular}{|c|c|c|c|c|}
\hline Sexo & Identificação & $\begin{array}{c}\Sigma \text { PCBs } \\
\text { Gordura ng.g } \\
\end{array}$ & $\begin{array}{c}\Sigma \text { PCBs } \\
\text { Fígado ng.g } \\
\end{array}$ & $\begin{array}{l}\Sigma \text { PCBs } \\
\text { Rim ng.g-1 } \\
\end{array}$ \\
\hline \multicolumn{5}{|l|}{ Machos } \\
\hline & CM16 & n.d. & n.d. & n.d. \\
\hline & CM21 & n.d. & n.d. & n.d. \\
\hline & CM22 & n.d. & n.d. & n.d. \\
\hline & CM24 & n.d. & n.d. & n.d. \\
\hline & CM26 & 26,0 & n.d. & n.d. \\
\hline & CM27 & 3,1 & n.d. & n.d. \\
\hline \multirow[t]{21}{*}{ Fêmeas } & CM01 & 48,9 & 14,2 & 6,5 \\
\hline & CM02 & 30,7 & n.d. & n.d. \\
\hline & CM03 & 2,3 & 17,4 & 37,7 \\
\hline & CM04 & 3,3 & n.d. & n.d. \\
\hline & CM05 & n.d. & 7,0 & 21,0 \\
\hline & CM06 & 32,4 & 15,2 & n.d. \\
\hline & CM07 & 4,1 & 3,3 & n.d. \\
\hline & CM08 & 37,0 & 17,0 & 3,0 \\
\hline & CM09 & n.d. & 6,8 & n.d. \\
\hline & CM10 & n.d. & n.d. & n.d. \\
\hline & CM11 & 17,7 & n.d. & n.d. \\
\hline & CM12 & n.d. & n.d. & n.d. \\
\hline & CM13 & n.d. & n.d. & n.d. \\
\hline & CM14 & 5,3 & n.d. & n.d. \\
\hline & CM15 & 4,0 & n.d. & n.d. \\
\hline & CM17 & n.d. & n.d. & n.d. \\
\hline & CM18 & 3,9 & n.d. & n.d. \\
\hline & CM19 & n.d. & 6,5 & n.d. \\
\hline & CM20 & 37,0 & n.d. & n.d. \\
\hline & CM23 & n.d. & n.d. & n.d. \\
\hline & CM25 & n.d. & n.d. & n.d. \\
\hline Ocorrência (\%) & & 52 & 30 & 15 \\
\hline Média & & 15,0 & 5,1 & 4,0 \\
\hline Mediana & & 11,5 & 10,6 & 13,7 \\
\hline Amplitude & & $2,3-48,9$ & $3,3-17,4$ & $3,0-37,7$ \\
\hline
\end{tabular}



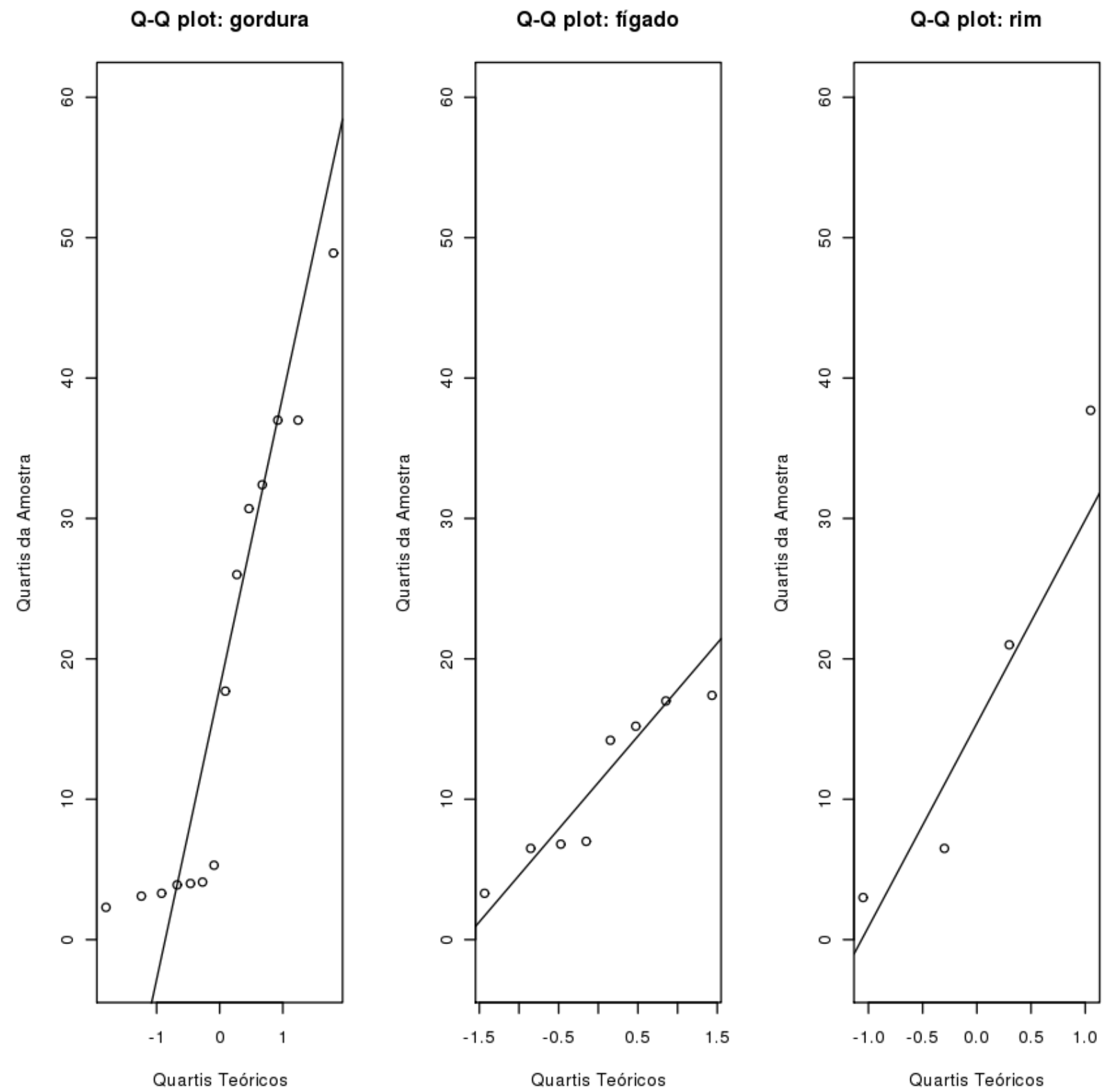

Figura 16. Avaliação da normalidade dos dados usando gráfico quantil-quantil (q-q) para amostras de tecidos de C. mydas. 
Em geral, a bioacumulação de organoclorados é bastante influenciada pelo sexo dos organismos principalmente na fase adulta quando as fêmeas excretam esses compostos através dos ovos durante o período reprodutivo (MATTHEWS, 1984). Dessa forma, machos e fêmeas devem ser tratados como grupos distintos. No entanto, neste trabalho, devido ao pequeno número de amostras que se referem a indivíduos juvenis, optou-se por agrupar machos e fêmeas em um único grupo para futuras comparações entre tecidos e diferentes estudos.

Para verificar se havia diferença estatística nas concentrações de PCBs entre os diferentes tecidos, os dados foram primeiramente avaliados quanto à normalidade usando uma análise de quantile-quantile (Figura 16). Como estes não apresentaram distribuição normal, optou-se por um teste não-paramétrico de Kruskal-Wallis com nível de significância de 95\%. Não foram encontradas diferenças estatisticamente significativas nas concentrações de PCBs entre gordura, fígado e rim. Todas as amostras analisadas estão dentro do mesmo intervalo de concentração (Figura 17). A ausência de diferença entre os tecidos deve-se ao pequeno número amostral e alta variabilidade nos dados. 


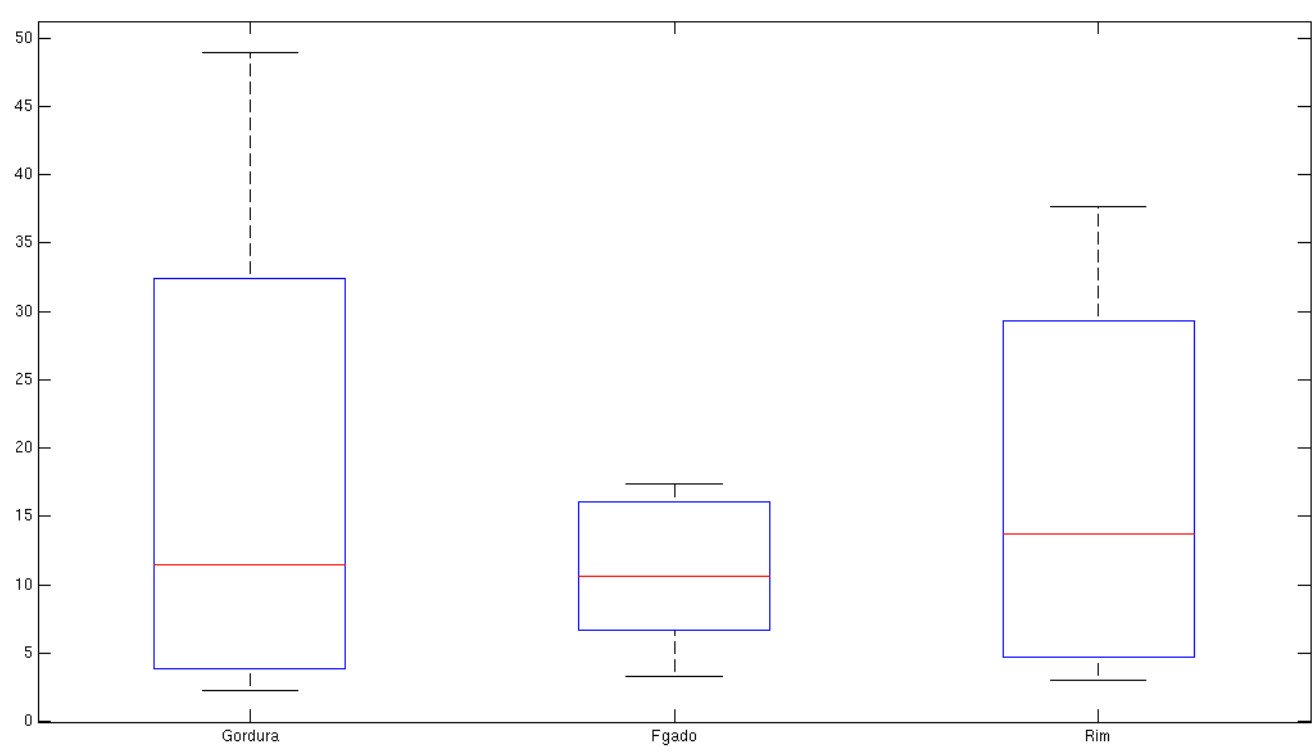

Figura 17. Boxplot da concentração de PCBs nos tecidos de gordura, fígado e rim em $C$. mydas.

Classificando os PCBs de acordo com o número de cloros $(1 \mathrm{Cl}$ a $4 \mathrm{Cl}$ - PCBs leves; 5 $\mathrm{Cl}$ PCBs intermediários; $6 \mathrm{Cl}$ a $10 \mathrm{Cl}$ PCBs pesados) pode-se observar que os compostos leves e intermediários são predominantes nas amostras analisadas. Mckenzie et al. (1999), Garder et al. (2003), Storelli et al. (2007) e Cobb (1997) encontraram a mesma tendência em outras espécies.

Os compostos organoclorados são absorvidos pelas tartarugas marinhas através da alimentação e na fase reprodutiva são transferidos da fêmea para os ovos. O grau de bioacumulação destes contaminantes depende da posição trófica de cada uma das espécies no ciclo alimentar marinho e o seu habitat.

Em trabalho realizado por AGUIRRE (1994) em Chelonia mydas no Havai também não foram observadas concentrações acima do L.D.= 0,1 ppm em indivíduos juvenis e nos ovos analisados. As concentrações encontradas em outras espécies por GARDENER (2003) no Golfo da Califórnia no México, em Chelonia mydas agassizzi apresentaram as seguintes 
variações na gordura: $\Sigma$ DDT $=$ Não detectado (n.d.) $-49,5$ ng. $\mathrm{g}^{-1}, \Sigma$ clordanas $=$ n.d. $-12,2$ ng. $\mathrm{g}^{-1}, \mathrm{HCB}=$ n.d., aldrin e dieldrin = n.d., endosulfan I e II = n.d. $-7,8$ ng. $\mathrm{g}^{-1}$, endrin = n.d.3,9 ng.g ${ }^{-1}$, na Caretta caretta na gordura e no músculo = n.d. O único pesticida detectado foi endosulfan I e II = 3,9 ng.g ${ }^{-1}$ no fígado. MCKENZIE (1999) analisou amostras Chelonia mydas do Mar Mediterrâneo e encontrou na gordura de indivíduos jovens concentrações de: endrin $=<3,2 \mu \mathrm{g} / \mathrm{kg}$, dieldrin $=<3,0-3,5, \mathrm{DDD}<3,2, \mathrm{DDE}=2,4-19,0, \mathrm{DDT}=<3,2$. Nos ovos observou-se as seguintes concentrações: endrin $=<0,3 \mu \mathrm{g} / \mathrm{kg}$, dieldrin $=<0,3, \mathrm{DDD}<$ $0,3, \mathrm{DDE}=2,3, \mathrm{DDT}=<0,5$. As concentrações encontradas em filhotes foi de: endrin $=<0,4$ $\mu \mathrm{g} / \mathrm{kg}$. dieldrin $=<0,3, \mathrm{DDD}<0,4, \mathrm{DDE}=0,5, \mathrm{DDT}=<3,4$ (Tabela 08).

Tabela 08. Comparação na concentração $\left(n g \cdot g^{-1}\right)$ de compostos organoclorados em diferentes espécies de tartaruga marinha.

\begin{tabular}{|c|c|c|c|c|c|c|c|c|c|c|}
\hline Ano & Local & Espécie & Maturidade & $\sum \mathrm{PCBs}$ & $\Sigma$ DDTs & $\sum \mathrm{HCHs}$ & CHLs & $\mathrm{HCB}$ & Mirex & Ref \\
\hline $\begin{array}{l}2007 \\
\text { a } \\
2008\end{array}$ & Ubatuba - SP & Chelonia mydas & Juvenil & $\begin{array}{c}<1,6- \\
17,4\end{array}$ & $<1,6$ & $<1,6$ & $<1,6$ & $<1,6$ & $<1,6$ & 1 \\
\hline 1994 & Havaí & Chelonia mydas & Juvenil & n.d. & n.d. & n.d. & n.d. & n.d. & n.d. & 2 \\
\hline 2003 & Carolina do Norte & Caretta caretta & Juvenil & 8,92 & $0,579 *$ & - & 0,265 & & 0,034 & 3 \\
\hline $\begin{array}{l}1999 \\
\text { a } \\
2001\end{array}$ & Mar Mediterrâneo & Caretta caretta & Juvenil & $\begin{array}{l}0,54- \\
297,4\end{array}$ & $\begin{array}{l}0,12- \\
73,61\end{array}$ & & & n.d & & 4 \\
\hline \multirow[t]{3}{*}{$\begin{array}{l}1994 \\
\mathrm{a} \\
1996\end{array}$} & Mar Mediterrâneo & Chelonia mydas & Juvenil. & $\begin{array}{l}39,0- \\
261,0\end{array}$ & $1,2-23,0$ & & $\begin{array}{c}<0,3- \\
3,2\end{array}$ & & & 5 \\
\hline & & Caretta caretta & Juvenil & $\begin{array}{l}775,0- \\
893,0\end{array}$ & $\begin{array}{l}49,0- \\
739,0\end{array}$ & & $\begin{array}{c}\text { n.d. - } \\
33,0\end{array}$ & & & 5 \\
\hline & & $\begin{array}{l}\text { Dermochelys } \\
\text { coriacea }\end{array}$ & Adulto & $\begin{array}{l}3,1- \\
178,0\end{array}$ & $\begin{array}{c}14,0- \\
58,0\end{array}$ & & $\begin{array}{l}2,3- \\
22,0\end{array}$ & & & 5 \\
\hline \multirow[t]{3}{*}{2003} & México & C. mydas agassizi & & $\begin{array}{l}\text { n.d - } \\
49,5\end{array}$ & $\begin{array}{l}\text { n.d }- \\
12,2\end{array}$ & & $\begin{array}{c}\text { n.d. - } \\
65,1\end{array}$ & n.d. & & 6 \\
\hline & & $\begin{array}{l}\text { Lepidochelys } \\
\text { olivacea }\end{array}$ & & 18,4 & 5,1 & & 8,1 & n.d. & & 6 \\
\hline & & Caretta caretta & & n.d. & n.d. & & n.d. & n.d. & & 6 \\
\hline 2002 & Flórida & Caretta caretta & Ovo & $\begin{array}{l}0,790- \\
1010,0\end{array}$ & $\begin{array}{l}1,190- \\
344,0\end{array}$ & $\begin{array}{l}0,020- \\
2,050\end{array}$ & $\begin{array}{c}0,827- \\
175,0\end{array}$ & & $\begin{array}{l}0,009- \\
7,520\end{array}$ & 7 \\
\hline 1974 & Ascension Island & Chelonia mydas & Ovo & $\begin{array}{l}20,0- \\
220,0\end{array}$ & n.d. $-9,0$ & n.d. & n.d. & n.d. & n.d. & 8 \\
\hline
\end{tabular}




\begin{tabular}{|l|l|l|l|c|l|l|l|l|l|l|}
\hline 1994 & Mar Adriático & Caretta caretta & Juvenil & $136,0-$ & & & & & & 9 \\
\hline
\end{tabular}

$* 4,4-\mathrm{DDE}$

(1) Presente estudo; (2) AGUIRRE, 1994; (3) KELLER, 2004; (4) STORELLI, 2007; (5) MCKENZIE, 1999; (6) GARDNER, 2003; (7) ALAVA, 2006; (8) THOMPSON, 1974; (9) CORSOLINI, 2000.

As semelhanças na distribuição dos congêneres do PCBs nas tartarugas marinhas podem ser o resultado de atividades metabólicas das tartarugas. Porém, sem o conhecimento da composição de PCBs nas presas destes organismos, isto é apenas uma suposição.

A distribuição inicial dos PCBs é determinada por fatores biofísicos como volume de tecido, relação tecido/sangue, absorção de proteínas e taxa de perfusão. O fígado e o músculo são os primeiros depósitos, porque tem alta perfusão sanguínea e afinidade a esses compostos; e por ter o maior volume de tecido respectivamente. Porém, os PCBs têm maior afinidade com tecidos ricos em lipídios e o processo de redistribuição é mais lento embora seja simultâneo a distribuição inicial. (MATTHEWS \& DEDRICK, 1984).

A diferença nos níveis de concentração depende da quantidade de lipídios presentes nos diferentes tecidos sendo esta uma característica comum na maioria dos organismos. A acumulação de PCBs nas tartarugas analisadas neste trabalho segue a tendência mostrada por alguns autores como STORELLI (2007), MCKENZIE (1999) e CORSOLINI (2000), que é a de maior ocorrência dos analitos em tecidos na qual há maior concentração de lipídios: de gordura $(52 \%)>$ fígado $(30 \%)>\operatorname{rim}(15 \%)$ (Figura 18). As concentrações nas amostras de músculo ficaram abaixo do limite de detecção do método. 


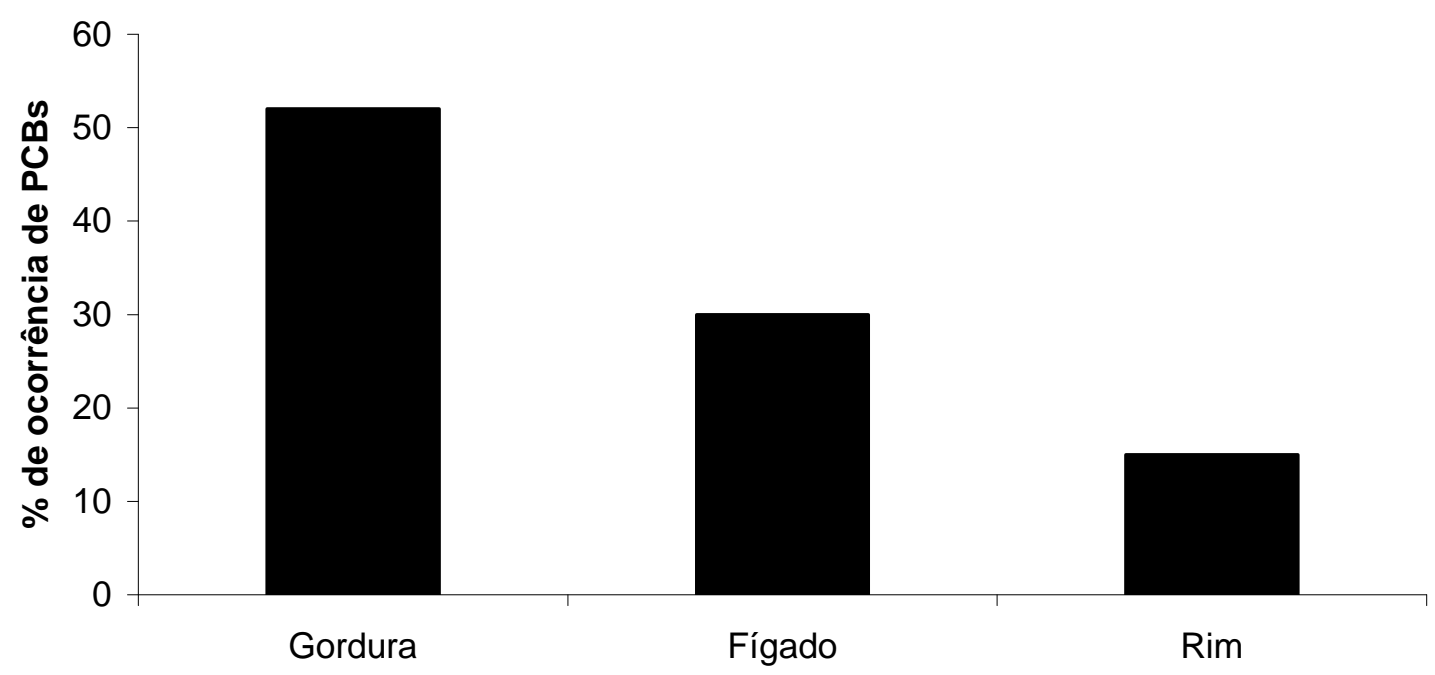

Figura 18. Perfil da ocorrência dos PCBs na gordura, fígado e rim em tartarugas.

Nota-se que para cada tecido analisado existe um perfil diferente de ocorrência de congêneres de acordo com o número de cloros, sendo que na gordura a maior ocorrência são de congêneres com seis cloro, no fígado de congêneres de cinco cloros e no rim de congêneres com 4 cloros. Esta diferença entre os tecidos pode estar relacionada à lipofilicidade de cada um, sendo que quanto maior o teor de lipídios maior é o número de cloros do congêneres que ficaram retidos nestes tecidos (Figura 19). 


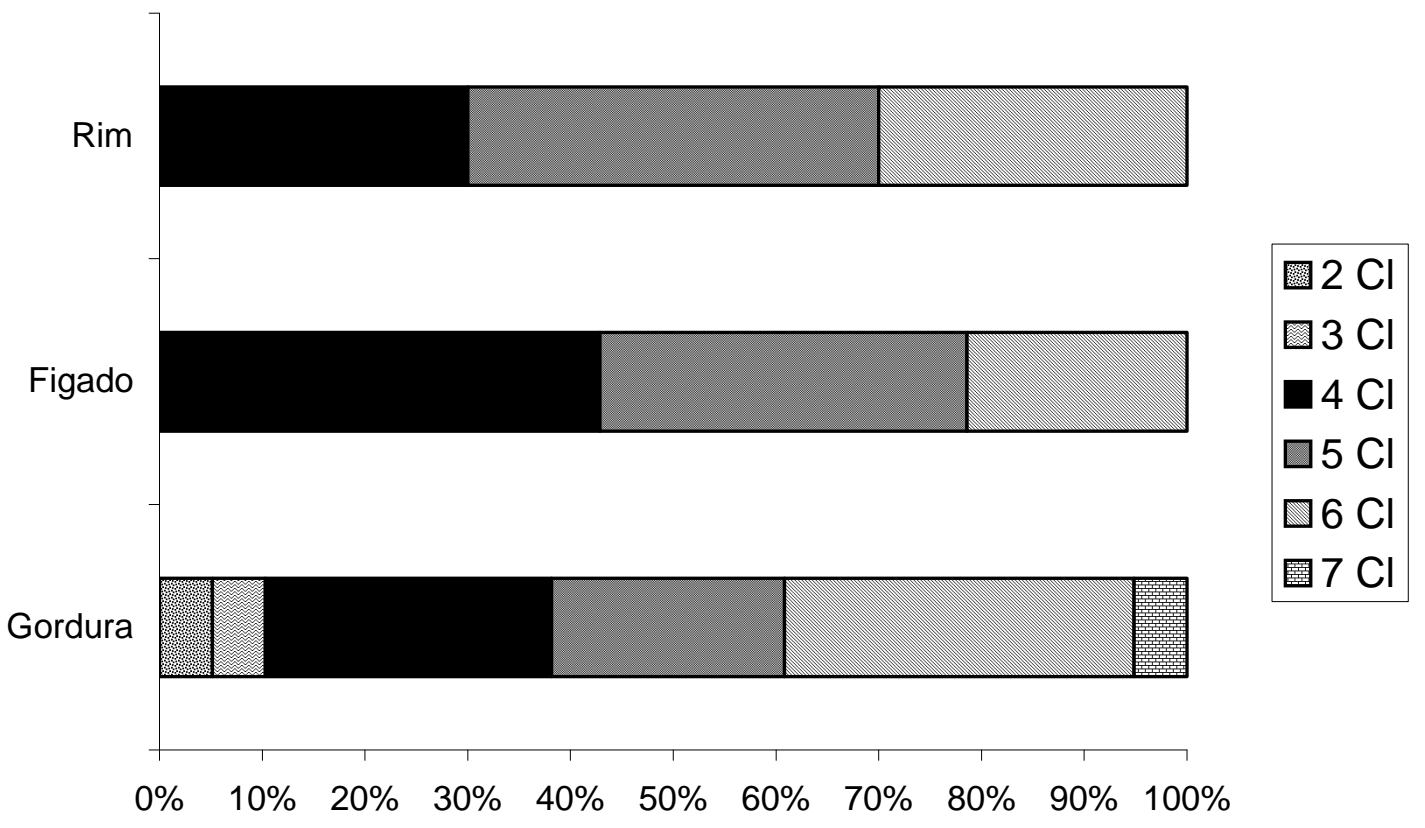

Figura 19. Frequência de ocorrência de PCBs conforme o número de cloros por tecidos.

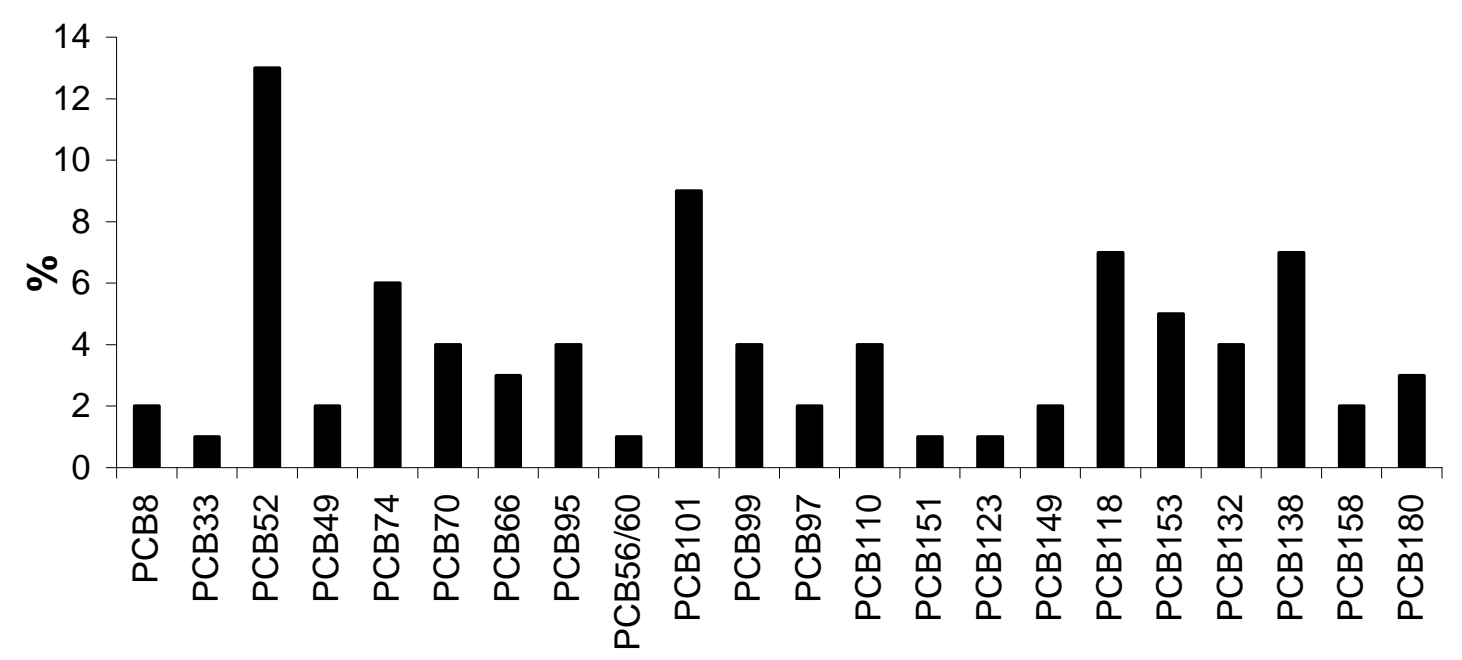

\section{Congêneres}

Figura 20. Frequência de ocorrência dos congêneres nas amostras de gordura analisadas.

Os congêneres predominantes foram os PCBs 52 e 44 (tetraclorados), PCBs 99 e 101 (pentaclorados) e PCBs 118, 153, 132 e 138 (hexaclorados) (Figura 20). 
Comparando-se trabalhos realizados com diferentes espécies (STORELLI et al. (2007), MCKENZIE et al. (1999), GARDER et al. (2003), RYBITSKI et al. (1995), CORSOLINI et al. (2000), KELLER et al. (2004), AGUIRRE et al. (1994)) nota-se a tendência de maior concentração para Lepidochelis olivacea $>$ Caretta caretta $>$ Chelonia mydas $=$ Dermochelis coriacea, provavelmente é baseado nos diferentes hábitos alimentares de cada espécie.

Lake et al. (1994) analisaram amostras de fígado de Lepidochelis Kempii e observaram que as concentrações de $\mathrm{PCBs}$ e $p, p^{\prime} \mathrm{DDE}$ em fígado de tartarugas juvenis são geralmente mais altos em relação a amostras de espécimes adultos, que pode ocorrer porque as concentrações se diluem de acordo com o crescimento do individuo. Não há estudos fazendo essa comparação com a espécie Chelonia mydas, entretanto essa espécie possa ter a mesma tendência, levando-se em consideração que quando filhote é onívora e a partir do momento que se torna herbívora não adquiri mais estes compostos e tem aumento de massa corpórea.

As amostras analisadas neste trabalho apresentam baixos níveis de contaminantes organoclorados comparados a concentrações apresentadas em trabalhos realizados em outras regiões mais desenvolvidas como no Mar Mediterrâneo (LAKE et al., 1994; MCKENZIE et al., 1999; CORSOLINI et al., 2000).

\section{Conclusão}

Não foi observada relação na concentração dos congêneres entre macho e fêmea e entre indivíduos saudáveis e debilitados.

Os resultados desse estudo indicam baixa contaminação por organoclorados em $C$. mydas na região sul e sudeste. Sugere-se que os baixos níveis encontrados nesta espécie estão relacionados principalmente a sua dieta alimentar, pois $C$. mydas é basicamente herbívora. Além disso, os espécimes eram todos juvenis e o local de coleta é uma região não industrializada. 
A presença destes compostos em $C$. mydas pode ser uma evidência de sua dispersão global ou conseqüência de seu comportamento migratório. O resultado desses contaminantes em tartarugas marinhas é um trabalho inédito no Brasil e pode contribuir para os estudo da poluição de organoclorados em organismos marinhos e sua distribuição nos diferentes níveis tróficos.

\section{Recomendações}

Com base no presente trabalho sugere-se:

- Realizar análises de organoclorados nos ovos e filhotes da espécie C. mydas para avaliar a transferência desses compostos às futuras gerações.

- Realizar análises destes contaminantes nas demais espécies que ocorrem no Brasil Caretta caretta, Lepidochelys olivacea, Eretmochelys imbricata e Dermochelys coriacea.

- Além da análise de pesticidas organoclorados e PCBs, realizar também análises de metais pesados e PBDEs, pois também são compostos tóxicos e ainda não há registros na literatura sobre análise desses compostos em tartarugas marinhas no Brasil. 


\section{Bibliografia:}

AGUIRRE, A. A., BALAZS, G. H., ZIMMERMAN, B. \& GALEY, F. D. 1994. Organic contaminants and trace metal in the tissues of green turtles (Chelonia mydas) afflicted with fibropapillomas in the Hawaiian Islands. Marine Pollution Bulletin, vol. 28, $\mathrm{n}^{\mathrm{o}} 2$, p.109-114.

ALAVA, J. J., KELLER, J. M., KUCKLICK, J.R., WYNEKEN, J. CROWDER, L. \& SCOTT, G. I. 2006. Loggerhead sea turtle (Caretta caretta) egg yolk concentrations of persistent organic pollutants and lipid increase during the last stage of embryonic development. Science of the Total Environment, vol. 367, p 170-181.

ASSUMPÇÃO, J. C. 2002. Endrin. In: Fernícola, N. A. G. G. \& Oliveira, S. S. (orgs), Poluentes orgânicos persistentes. Cadernos de referência ambiental, vol. 13, p. 285-301.

BAIRD, C. 2002. Química ambiental. $2^{\circ}$ Ed, p. 622.

BALAZS, G. H. \& POOLEY, S. G. eds. 1991. Research plan for marine turtle fibropapilloma. US Departament of Commerce/National Oceanic \& Atmospheric Administration/National Marine Fisheries Service, March 1991, NOAA Tech. Mem. NMFSSWFSC-156.

BALDASSIN, P.J., TANIGUCHI, S., MONTONE, R.C. 2002. Determinação de compostos organoclorados em ovos de tartarugas marinhas (Caretta caretta) em Guriri. ES. In Anais: VI Congresso e XI Encontro da Associação Brasileira de Veterinários de Animais 
Selvagens. realizado em Vitória, ES. Caderno de Resumos.

BAPTISTOTTE, C., RIETH, D. B., BECKER, J. H., LOPEZ, G., CASTILHOS, J. C., LIMA, E. H. S. M., BELlini, C., MATUSHIMA, E. R. \& BARATA, P. C. R. 2001. Prevalência de fibropapilomas em tartarugas marinhas em áreas de alimentação no Brasil. In: Anais do V Congresso e X Encontro da Associação Brasileira de Veterinários de Animais Selvagens (ABRAVAS), p.29.

BJORNDAL, 1997. Foraging ecology and nutrition of sea turtles. In Lutz, P. L., \& Musick, J. A. (orgs). The biology sea turtles. p. 199-231.

CETESB. 1978. Poluição das Águas no Estuário e Baia de Santos. Relatório CETESB. São Paulo: vol. 1.

CLARK, R. B. 2001. Marine pollution. Claredon Press, Oxford, $5^{\text {rd }}$ Ed, 231p.

COBB, G. P. \& WOOD, P. D. 1997. PCB concentrations in eggs and chlorioallantoic membranes of loggerhead sea turtles (Caretta caretta) from the Cape Romain National Wildlife Refuge. Chemosphere, vol. 34, n ${ }^{\circ} 3$, p. 539-549.

CORSOLINI, S., AURIGI, S. \& FOCARDI, S. 2000. Presence of polychlorobiphenyls (PCBs) and coplanar congeners in the tissues of the mediterranean loggerhead turtle Caretta caretta. Marine Pollution Bulletin, vol. 40, nº 11, p. 952-960. 
DENOUX, G. GARDINALI, P. \& WADE, T. L. 1998. Quantitative determination of nuclear aromatic hydrocarbons by gas chromatography/mass spectrometry (GC/MS) Selected Ion Monitoring mode. LAUENSTEIN, G. G. \& A. Y. CANTILLO (Eds.) In: NOAA Technucak Memoradum NOS ORCA 130, National Status and Trends Program for Marine Environmental Quality, NOAA, US DoC, 129 - 139.

FAO SPECIES CATALOGUE. 1990. Sea turtles of the world. An annotated and illustrated catalogue of sea turtle species know to date. FAO Fisheries Synopis. Rome, FAO n 125 , vol 11. p. 81 .

FERNíCOLA, 2002. Mirex. In: Fernícola, N. A. G. G. \& Oliveira, S. S. (orgs). Poluentes orgânicos persistentes, Cadernos de referência ambiental, vol. 13, p. 419-446.

GALLO, B. M. G., MACEDO. S., GIFFONI, B.B., BECKER, J.H. \& BARTA, P. C. R., 2000. A base do projeto Tamar-ibama em Ubatuba (Estado de São Paulo, Brasil): Conservação das tartarugas marinhas em uma área de alimentação. In: Anais da XIII Semana Nacional de Oceanografia, Itajaí, SC, p. 500-502.

GALLO, B. M. G., MACEDO, S., GIFFONI, B. B., BECKER, J. H. \& BARATA, C. R. 2006. Sea turtle conservation in Ubatuba, Southeastern Brazil, a feeding area with incidental capture in coastal fisheries. Chelonian Conservation and Biology, vol. 5(1), p. 93-101.

GARDNER, S. C., PIER, M. D., WESSELMAN, R. \& JUÁREZ, A. 2003. Organochlorine contaminants in sea turtles from the Eastern Pacific. Marine Pollution Bulletin, vol. 46, p. 1082-1089. 
GUEBERT, M. F. 2004. Ecologia alimentar e mortalidade da Tartaruga marinha

Chelonia mydas no litoral do Estado do Paraná. Monografia. Universidade Federal do Paraná, Brasil, 36p.

GUEBERT, M. F., MONTEIRO-FILHO, E. L. A. \& ROSA, L. 2007. Ecologia alimentar da tartaruga verde Chelonia mydas no litoral do estado do Paraná. Sul do Brasil. XXI Congresso Latino-Americano de Ciências do Mar.

HERBEST, L. H. 1994. Fibropapillomatosis of marine turtles. Annual Reviews of Fish. Diseases, vol. 4, p. 389-425.

HUTCHINSON, J. \& SIMMONDS, M. 1991. A Review of the effects of pollutions on marine turtles. A Greenpeace Ecotoxicology Project. Greenpeace International. London. England.

JESUS, M. G. S. 2002. DDT. In: Fernícola, N. A. G. G. \& Oliveira, S. S. (orgs). Poluentes orgânicos persistentes. Cadernos de referência ambiental, vol. 13, p.161-189.

JÚNIOR, A. N. M., MORAES, R. B. C. \& MAURAT, M. C. 2002. Poluição Marinha. In: Pereira, R. C. \& Soares-Gomes, A. (orgs). Biologia Marinha, Editora Interciência, p. 311-334.

LAKE, J. L., HAEBLER, R., MCKINNEY, R., LAKE, C. A., \& SADOVE, S. S. 1994. PCBs and other chlorinated organic contaminants in tissues of juvenile kemp's ridley turtles (Lepidochelys Kempi). Marine Environmental Research, vol. 38, p. 313-327. 
LIMA, 2002. Heptacloro. In: Fernícola, N. A. G. G. \& Oliveira, S. S. (orgs). Poluentes orgânicos persistentes. Cadernos de referência ambiental, vol. 13, p. 345-382.

LIMA, E. H. S. M. \& EVANGELISTA, L. E. V. 1997. Sobre a captura acidental em curral de pesca da tartaruga marinha Dermochelys coriacea em Almofala - Ceará. In: CONGRESSO NORDESTINO DE ECOLOGIA. Ilhéus. Anais. Ilhéus: EDITUS, p. 248.

KELLER, J. M., KUCKLICK, J. R., STAMPER, M. A., HARMS, C. A. \& MCCLELLANGREEN, P. D. 2004. Associations between organochlorine contaminant concentrations and clinical health parameters in loggerhead sea turtles from North Carolina. USA. Environmental Health Perspectives, vol. 112, nº 10, p. 1074-1079.

KELLER, J. M., KUCKLICK, J. R. \& MCCLELLAN-GREEN, P. D. 2004. Organochlorine contaminants in loggerhead sea turtles blood: Extraction techniques and distribution among plasma and red blood cells. Environmental Health Perspectives. vol. 46, p. 254-264.

KLEMENS, J. A., WIELAND, V. J., FLANAGIN, J. A., FRICK, R. G. \& HARPER. 2002. A cross-taxa survey of organochlorine pesticide contamination in a Costa Rican wildland. Environmental Pollution, vol. $\mathrm{n}^{\circ}$ 122, p. 245-251.

MARCOVALDI, M. A. \& MARCOVALDI, G. G. 1999. Marine turtles of Brazil the history and structure of Projeto TAMAR-IBAMA. Biological Conservation, vol. 91, p. 3541. 
MARCovaldi, M. A., Silva, A. C. C. D., GAllo, B. M. G., BAPtistotTe, C., VIEITAS, C. F., BELLINI, C., LIMA, E. H. S. M., DE CASTILHOS, J. C., THOMÉ, J. C. A. \& SANCHES, T. M. 2000. Atuação do Projeto Tamar-Ibama em áreas de alimentação das tartarugas marinhas no Brasil. In: Anais da XIII Semana Nacional de Oceanografia, Itajaí, SC, p. 497-499.

MATTHEWS, H. B. \& DEDRICK, R. L. 1984. Pharmacokinetics of PCBs. Ann. Rev. Pharmacol. Toxicol, vol.24, p. 85-103.

MEYLAN, A. B. \& MEYLAN, P. A. 2000. Introducción a la evolución. historias de vida y biología de las tortugas marinas. In. Eckert, K. L., Bjorndal, K. A., Abreu-Grobois, F. A. \& Donnelly, M. (orgs). Técnicas de investigación y manejo para la conservación de las tortugas marinas, p. 3-5.

MCKENZIE, C., GODLEY, B. J., FURNES, R. W. \& WELLS, D. E. 1999. Concentrations and patterns of organochlorine contaminants in marine turtles from Mediterranean and Atlantic waters. Marine Environmental Research, vol. 47, p. 117-135.

MORTIMER, J. A. 1981. The feeding ecology of the west Caribbean green turtle (Chelonia mydas) in Nicaragua. Biotropica, vol. 13(1), p. 49-58.

NETO, J. M. 2002. Aldrin. In: Fernícola, N. A. G. G. \& Oliveira, S. S. (orgs). Poluentes orgânicos persistentes. Cadernos de referência ambiental, vol. 13, p. 21-53. 
OLIVEIRA, S. S. 2002 . Clordano. In: Fernícola, N. A. G. G. \& Oliveira, S. S. (orgs). Poluentes orgânicos persistentes. Cadernos de referência ambiental, vol. 13, p. 123-155.

PENTEADO, J. C. P. \& VAZ, J. M. 2001. O legado das bifenilas policloradas (PCBs). Química Nova, vol. 24, nº 3, p. 390-398.

PNUMA, 2002. Programa de Las Naciones Unidas para el Medio Ambiente (Productos Químicos). Evaluación regional sobre substancias tóxicas, 92p.

PRITCHARD, P. C. H. \& MORTIMER, J. A. 2000. Taxonomía, morfología externa e identificación de las especies. In. Eckert, K. L., Bjorndal, K. A., Abreu-Grobois, F. A. \& Donnelly, M. (orgs). Técnicas de investigación y manejo para la conservación de las tortugas marinas, p. 3-5.

REISSER, J., PROIETTI, M. C. \& SAZIMA, I. 2007. Ecologia da tartaruga-verde (Chelonia mydas) na Reserva Biológica Marinha do Arvoredo, sul do Brasil, XXI Congresso Latino-Americano de Ciências do Mar.

RYBITSKI, M.J., HALE, R.C. \& MUSICK, J.A. 1995. Destribution of organoclorine pollutants in Atlantic sea turtles, Copeia, p. 379-390.

SALGADO, P. E. T. 2002. Bifenilas Policloradas. In: Fernícola, N. A. G. G. \& Oliveira, S. S. (orgs). Poluentes orgânicos persistentes, Cadernos de referência ambiental, vol. 13, p. 65-105. 
SANTAMARTA, J. 2001. Por um futuro sem contaminantes orgânicos persistentes. Agroecologia e Desenvolvimento Rural Sustentável, vol. 2, nº 1, p. 46-46.

SAZIMA, I. \& SAZIMA, M. 1983. Aspectos de comportamento alimentar e dieta da tartaruga marinha Chelonia mydas, no litoral norte paulista. Boletim Instituto Oceanográfico. São Paulo, vol. 32, nº 2, p. 199-203.

SCHANTZ, M. M., KOSTER, B. J., OAKLEY, L. M., SCHILLER, S. B. \& WISE, S. A. 1995. Certification of polychlorinated biphenyl congeners and chlorinated pesticides in a whale blubber Standard Reference Material. Analytical Chemistry, vol. 67(5), p. 901-910.

StORELli, M. M., BARONE, G. \& MARCOTRIGIANO, G. O. 2007. Polychlorinated biphenyls and other chlorinated organic contaminants in the tissues of Mediterranean loggerhead turtle Caretta caretta. Science of the Total Environment, vol. 373, p. 456-463.

TAMAR- IBAMA, 2005. Projeto Tamar-Ibama - Apostila de estagiários. Base de Ubatuba - SP. 61p

TOLEDO, H. H. B. 2002. Hexaclorobenzeno. In: Fernícola, N. A. G. G. \& Oliveira, S. S. (orgs). Poluentes orgânicos persistentes. Cadernos de referência ambiental, vol. 13, p.387-408.

TORDOIR, W. F., van SITTERT, N. J. 1994. Organochlorines. Toxicology, vol. 91, p. 5157. 
UNEP (United Nations Environment Programme), 2002. Regionally Based Assessment of Persistent Toxic Substances - Antarctica Regional Report.

WADE, T. L. \& CANTILLO, A. Y. 1994. Use of standards and reference materials in the measuremente of chlorinated hydrocarbon residues. Chemistry Workbook. NOAA Technical memorandum NOS ORCA 77. Silver Spring, Maryland. 59p.

WYNEKEN, J., BURKE, T. J., SALMON, M. \& PEDERSEN, D. K. 1988. Egg failure in natural and relocated sea turtle nests. Journal of Herpetology, vol. 22, no 1, p. 88-96.

YOGUI, G. T. 2002. Ocorrência de compostos organoclorados (pesticidas e PCBs) em mamíferos marinhos da costa de São Paulo (Brasil) e da Ilha Rei George (Antártica). Dissertação de Mestrado. Universidade de São Paulo, Brasil. 139p.

XAVIER, A. \& TORRES, E. 2002. Considerações sobre a fibropapilomatose em Chelonia mydas. in: Anais do XXIV Congresso Brasileiro de Zoologia, Itajaí, Sc.

www.atsdr.cdc.gov Acesso em 14/08/08

www.iucnredlist.org - Lista de espécies ameaçadas segundo a IUCN 2006 IUCN. Downloaded em 21/06/2007 
ANEXOS 


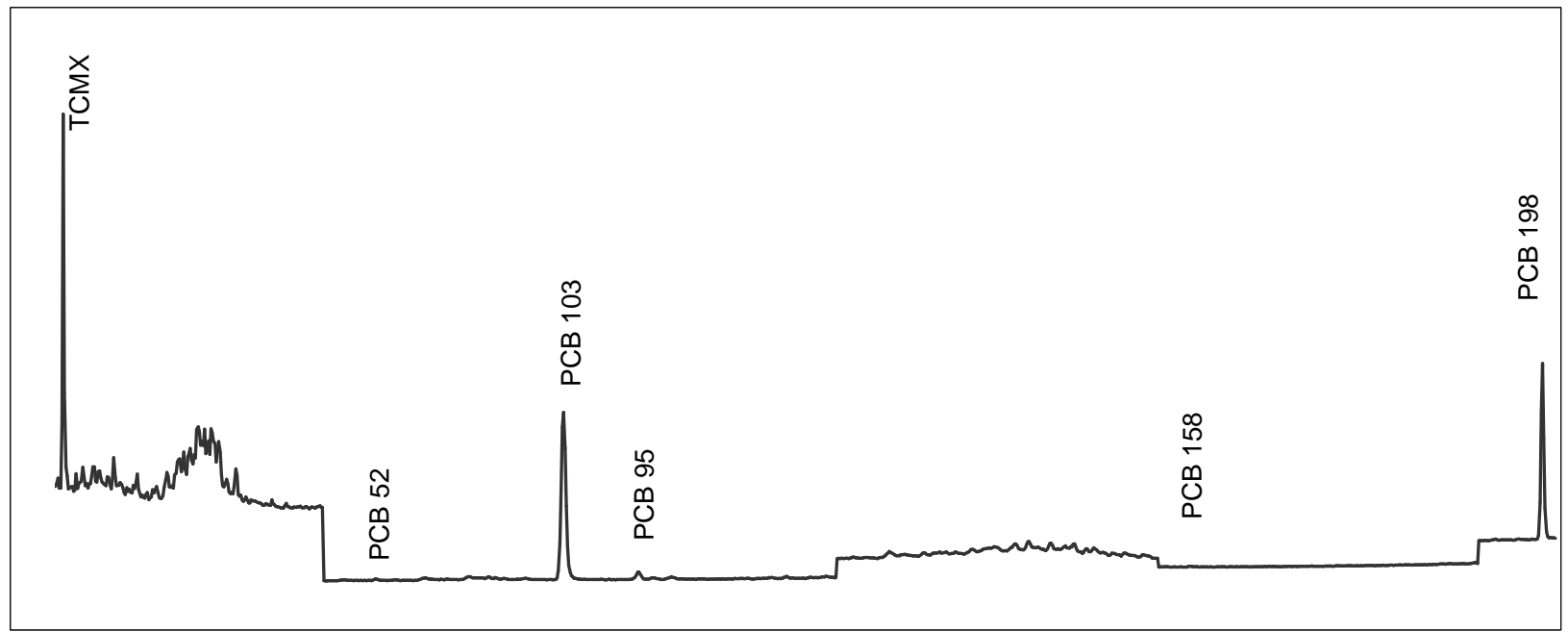

Cromatograma 1. PCBs em tecido de fígado (CMF01) analisados no GC-MS.

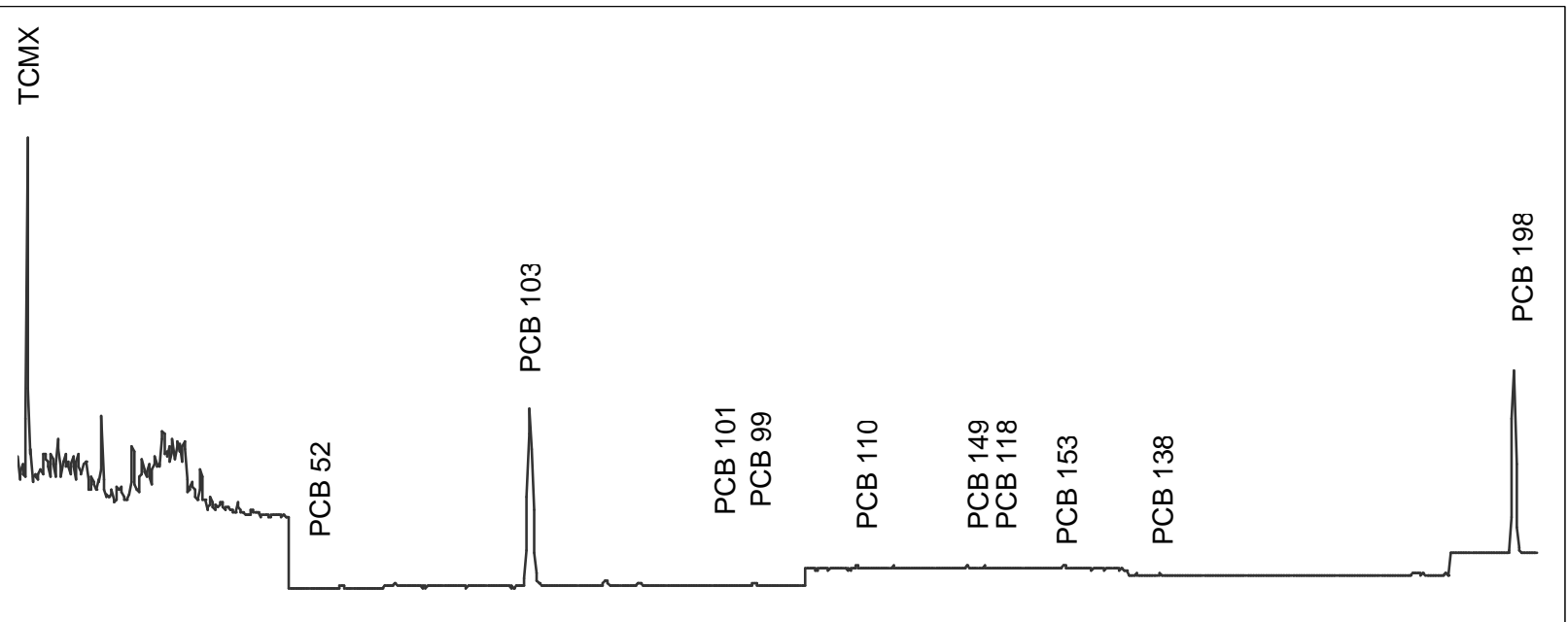

Cromatograma 2. PCBs em tecido de gordura (CMG01) analisados no GC-MS. 


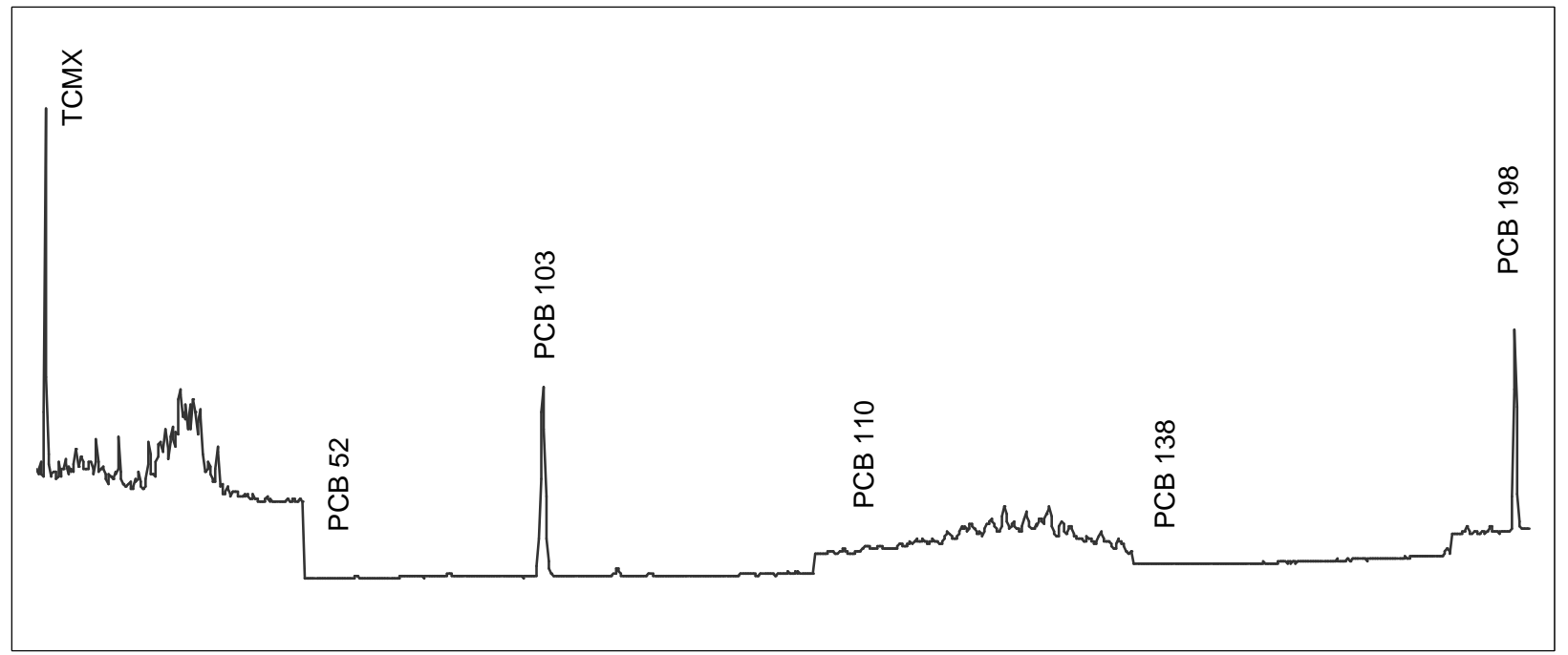

Cromatograma 3. PCBs no tecido de fígado (CMF03) analisados no GC-MS.

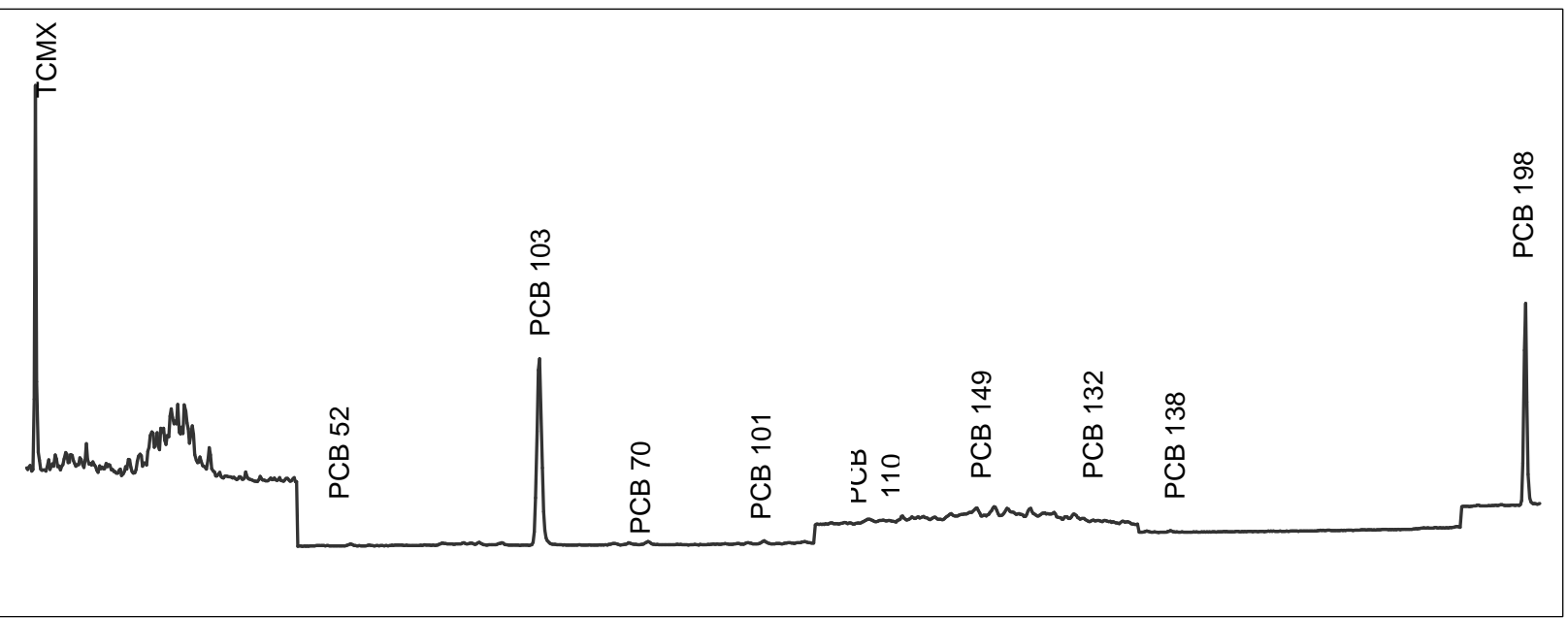

Cromatograma 4. PCBs em tecido de rim (CMR03) analisados no GC-MS. 